\title{
Función constitucional asignada a la pena: bases para un plan de política criminal

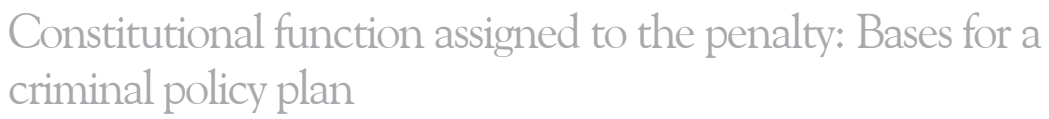

\section{ROMY CHANG KCOMT*}

Resumen: El presente trabajo busca efectuar un análisis en torno al tratamiento y las funciones que nuestra Constitución política asigna a la pena, y la manera como dicha institución se desarrolla en nuestro país con respecto a la pena abstracta (la impuesta por el legislador en cada tipo penal), la pena concreta (la impuesta por el juez luego de una individualización en cada caso concreto), y su ejecución en el ámbito penitenciario. Finaliza proponiendo algunas consideraciones para una eventual reforma legislativa conforme con un plan de política criminal que se encuentre dentro del marco constitucional.

Palabras clave: fines de la pena - teorías absolutas de la pena - retribucionismo penal - teorías relativas de la pena - prevención general - prevención especial clases de pena - pena abstracta - pena concreta - ejecución penitenciaria de la pena - pena máxima - pena mínima - reserva del fallo condenatorio sustitución de la pena privativa de libertad - suspensión de la ejecución de la pena - prisión preventiva

Abstract: This article intends to analyze treatment and functions assigned to the penalty by our Peruvian Constitution and the way this legal institution is conducted at the prescribed basic penalty level (imposed by the legislator in each type of criminal offence), the specific penalty level (imposed by the judge according to its individual characteristics in each case) and at the penitentiary enforcement level. Finally recommends some considerations for carrying out a possible legislative reform in accordance with a criminal policy plan within our constitutional framework.

Key words: punishment purposes - absolute theories of penalty - retributive justice - relative theories of penalty - general deterrence - special deterrence types of penalty - prescribed basic penalty - specific penalty - penitentiary enforcement - maximum sentence - minimum sentence - judgment reserve - custodial sentence substitution - suspended execution of sentence preventive custody

Magíster en Derecho Penal en la Universidad de Salamanca (España), doctoranda en Derecho Penal en la Universidad de Salamanca (España) y en la Universidad de São Paulo, profesora en la Facultad de Derecho y en la Facultad de Gestión y Alta Dirección de la Pontificia Universidad Católica del Perú, socia del Estudio Padilla \& Chang Abogados. Correo electrónico: romy.chang@ padillachang.com 
CONTENIDO:I.MARCO CONSTITUCIONALVIGENTEENEL PERÚ.-II. FINALIDADES Y FUNCIONES DE LA PENA EN EL PERÚ.- II.1.TEORÍAS ABSOLUTAS.- II.2. TEORÍAS RELATIVAS.- II.2.1. LA PREVENCIÓN ESPECIAL.- II.2.2. LA PREVENCIÓN GENERAL.- II.2.3. TEORÍAS DE LA UNIÓN.- III. DETERMINACIÓN LEGAL DE LA PENA: PENA ABSTRACTA.- III.1. PENA MÍNIMA Y PENA MÁXIMA ESTABLECIDAS POR EL LEGISLADOR PERUANO.- III.2. CLASES DE PENAS REGULADAS POR EL LEGISLADOR.- III.3. PENAS TOMADAS EN CUENTA POR EL LEGISLADOR PARA LA DETERMINACIÓN DEL MARCO LEGAL DE LA PENA EN LOS DELITOS DE LA PARTE ESPECIAL DEL CÓDIGO PENAL.IV. INDIVIDUALIZACIÓN JUDICIAL DE LA PENA: PENA CONCRETA.IV.1. RESERVA DEL FALLO CONDENATORIO.- IV.2. SUSTITUCIÓN DE LA PENA PRIVATIVA DE LIBERTAD.- IV.3. SUSPENSIÓN DE LA EJECUCIÓN DE LA PENA.IV.4. PRISIÓN PREVENTIVA.- V. EJECUCIÓN PENITENCIARIA: LAS NORMAS PENITENCIARIAS DEBEN SER ACORDES CON LOS FINES PREVENTIVOS DE LA PENA.- VI. PROPUESTAS CONCRETAS PARA UNA REFORMA LEGISLATIVA Y BASES PARA UN PROGRAMA INTEGRAL DE POLÍTICA CRIMINAL EN TORNO A LA CONCEPCIÓN CONSTITUCIONAL DE LA PENA.

I. MARCO CONSTITUCIONAL VIGENTE EN ELPERÚ El Estado peruano es uno que se precia de ser social y democrático de derecho, y en el que la «defensa de la persona humana y el respeto de su dignidad son el fin supremo de la sociedad y del Estado» ${ }^{1}$; es decir, a grandes rasgos, tiene como postulados esenciales: «la supremacía de la Constitución, la limitación del poder y el reconocimiento y tutela de los derechos fundamentales $»^{2}$. El Estado tiene el deber de velar por el bienestar de la sociedad, atendiendo las demandas de todos los sectores de esta, de manera que el contenido y alcance de su acción social deben ser determinados de conformidad con la regla de la democracia, que a su vez es establecida por el Parlamento ${ }^{3}$ (es decir, con la regla del consenso, la que implica libertad y pluralidad). En esta línea, el profesor García Pelayo descompone el postulado «Estado social y democrático de derecho» en tres elementos inseparables que se encuentran en constante interacción recíproca: (i) el objetivo social; (ii) la concepción ascendente o democrática del poder, y (iii) la sumisión de ambos términos a la disciplina del derecho ${ }^{4}$.

Dentro de este diseño constitucional, el derecho penal tiene el deber de «legitimarse como sistema de protección efectiva de los ciudadanos,

1 Artículo 1 de la Constitución Política del Perú.

2 Espinosa-Saldaña BarRera, Eloy. Prólogo a libro de Bustamante Alarcón, Reynaldo. Derechos fundamentales y proceso justo. Lima: ARA, 2001, p. 19.

3 Ver PÉREZ RoYo. Javier. Curso de derecho constitucional. Novena edición. Madrid: Marcial Pons, 2003, pp. 202 y 205.

4 García Pelayo, M. Citado por Cascajo Castro, José Luis. «Los fines de la pena en el orden constitucional». En Antonio Enrique Pérez Luño (coord.). Derechos humanos y constitucionalismo ante el tercer milenio. Madrid: Marcial Pons, 1996, p. 260. 
lo que le atribuye la misión de prevención $»^{5}$ (presupuesto de un Estado social $^{6}$ ), respecto de conductas que considere reprochables (presupuesto de un Estado democrático ${ }^{7}$ ). Por ello, el derecho penal tiene el deber de respetar la dignidad de todas las personas, mayorías y minorías, incluyendo al condenado, a quien debe ofrecer posibilidades para su resocialización y reinserción social ${ }^{8}$.

En el marco de este modelo de Estado, el artículo 139, numeral 22 de la Constitución peruana establece como principio y derecho de la función jurisdiccional que «el régimen penitenciario tiene por objeto la reeducación, rehabilitación y reincorporación del penado a la sociedad». Es decir, otorga a la pena una función preventiva especial positiva, léase resocializadora. Asimismo, el artículo IX del Título Preliminar del Código Penal peruano establece que la pena cumple tres funciones: la preventiva, la protectora y la resocializadora, mientras que las medidas de seguridad persiguen fines de curación, tutela y rehabilitación, lo que debiera transformarse en compromisos concretos en el sistema penitenciario peruano.

De lo expuesto se deduce que el ordenamiento jurídico peruano establece que la pena cumple una función preventiva tanto especial como general (teorías relativas de la pena), y su imposición debe sustentarse en la ulterior consecución de efectos sociales que influyan en el comportamiento del autor del delito o de la comunidad en general, de forma que se evite la comisión de aquel. De esta manera, una pena solo será legítima en la medida en que con ella se alcance un efecto social, pues una pena meramente retributiva (teoría absoluta), que únicamente apunte a la expiación del autor, iría contra los fundamentos de una Constitución democrática como la que se regula en Perú y del postulado social y democrático de derecho antes descrito.

Es innegable que la pena, en cierta medida, contiene un reproche personal para el autor del delito, en tanto este actuó contraviniendo la norma cuando pudo haber actuado de modo distinto ${ }^{10}$. Por esa razón, la pena no puede superar el límite de la culpabilidad del individuo y su función preventiva debe orientarse a los principios de exclusiva

5 MIR PUIG, Santiago. Derecho penal. Parte general. Sexta edición. Barcelona: Editorial Reppertor, 2002, p. 180.

6 MIR PUIG, Santiago. El derecho penal en el Estado social y democrático de derecho. Barcelona: Ariel, 1994, p. 37.

7 lbíd.

8 Ibíd., p. 40

9 Ver Roxin, Claus. Nuevas formulaciones en las ciencias penales. Homenaje al profesor Claus Roxin. Córdoba: Marcos Lerner, 2001, p. 213. Un desarrollo de los diversos fines que cumple la pena se hará en el punto siguiente.

$10 \mathrm{Al}$ respecto, el profesor Schunemann ha marcado una posición importante: Desde la óptica de la culpabilidad analiza los postulados del determinismo y del libre albedrío. SCHUNEMANN, Bernd. Temas actuales y permanentes del derecho penal después del milenio. Madrid: Tecnos, 2002, pp. 33 y ss.

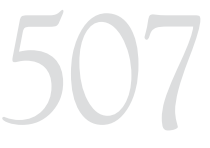

FUNCIÓN

CONSTITUCIONAL

ASIGNADA A LA

PENA:

BASES PARA UN

PLAN DE POLÍTICA

CRIMINAL

CONSTITUTIONAL

FUNCTION

ASSIGNED TO THE

PENALTY: BASES

FOR A CRIMINAL

POLICY PLAN 
protección de bienes jurídicos, de proporcionalidad y de culpabilidad ${ }^{11}$. Así, el artículo VIII del Título Preliminar del Código Penal establece que la pena no puede sobrepasar la responsabilidad por el hecho.

En resumen, no puede haber sanción penal sin culpabilidad: para imponer una pena es necesario prohibir únicamente las conductas que ex ante aparezcan capaces de producir un resultado desvalorado (desvalor objetivo de la conducta) de cara a un bien jurídico protegido. Así, el fundamento de la culpabilidad como límite al ius puniendi en un Estado social y democrático de derecho radica en la dignidad del ser humano, de modo que la imposición de la pena solo se justifica en el comportamiento contrario a derecho.

Por tanto, el sistema de penas diseñado en nuestra Constitución, en orden a nuestro modelo de Estado, establece la función preventiva de la pena y la descarta como mero mecanismo de expiación. Este es el presupuesto sobre el cual debe girar cualquier creación legislativa y cualquier interpretación de las normas de derecho interno. Es sobre la base de esta función que el marco constitucional asigna a la pena, que deben aplicarse las normas penitenciarias en el Perú.

\section{FINALIDADES Y FUNCIONES DE LA PENA EN EL PERÚ}

A lo largo de la historia, el derecho penal se ha visto constantemente sometido a un proceso de tensión entre sus fines. Así, mientras que por un lado busca tutelar los derechos de los individuos, por otro busca proteger a estos últimos de una intervención arbitraria del derecho ${ }^{12}$. En tal sentido, la legitimidad del derecho penal radica en su capacidad minimizadora del daño social, siguiendo lo que Silva Sánchez (desde una perspectiva teleológica-funcionalista) denomina «la regla del mínimo daño social», es decir, que el derecho penal reduzca su aportación de daño, sin que ello implique una pérdida de eficacia disuasoria ${ }^{13}$.

Sin embargo, del dilema de la legitimación y del porqué de la existencia del derecho penal, se deriva una segunda discusión en torno al «si y por qué castigar» ${ }^{14}$; es decir, al de los fines y funciones de la pena, discusión que refleja el proceso de tensión que es el punto de partida para la legitimación de la actuación penal, y que — tal como lo menciona

11 MIR PUIG, Santiago. El derecho penal en el Estado. Ob. cit., p. 37.

12 Baurmann, Michael. En Michael Baurmann y Hartmut Kliemt (eds.). Die moderne Gesellschaft im Rechtsstaat. Friburgo/Munich, 1990, pp. 111-112. Citado por Silva Sánchez, Jesús-María. Aproximación al derecho penal contemporáneo. Barcelona: Bosch, 1992, p. 185.

13 lbíd., pp. 183-185. Este autor propone la configuración de los siguientes elementos: «1) que el perjuicio que se procura evitar sea mayor que el que se causa; 2) que la pena sea efectiva para evitar esos perjuicios; y 3 ) que sea necesaria en el sentido de que no haya una medida más económica en términos de daño social que sea igualmente efectiva».

14 FerRAJOLI, Luigi. Derecho y razón. Teoría del garantismo penal. Madrid: Trotta, 1995, p. 247. 
Baurmann - fue reflejado a finales del siglo XIX por el tratadista Von Liszt al señalar que «la pena es una espada de doble filo: protección de bienes jurídicos mediante lesión de bienes jurídicos» ${ }^{15}$.

En la línea de lo expuesto, resulta necesario determinar los fines y funciones de la pena. Los fines responden a la pregunta del para qué sirva la pena, de cuál es el sustento dogmático que legitima su imposición, mientras que las funciones responden a la pregunta de cuáles son los efectos que la imposición de aquella generan en la sociedad ${ }^{16}$.

Respecto de los fines de la pena, en la medida en que esta supone inevitablemente la vulneración de derechos del individuo, resulta imprescindible buscar una justificación para que su imposición se encuentre acorde con los postulados constitucionales. Así, se puede establecer, en primera instancia, una doble legitimación de la pena: tanto en un nivel general de justificación del derecho penal y de la pena, léase como instrumento necesario para la consecución del fin general de protección de bienes jurídicos, como en un nivel particular de justificación en el caso en concreto, en la medida en que su imposición se determina a través de un sistema valorativo determinado ${ }^{17}$.

En tal sentido, la imposición de una pena ha encontrado en la doctrina diversas justificaciones, verbigracia las de prevención, resocialización, simple retribución, entre otras. En un esfuerzo de síntesis, estas teorías pueden ser agrupadas en tres rubros: teorías absolutas, teorías relativas y teorías de la unión. A continuación se describirán brevemente los aspectos más importantes de cada una de estas teorías:

\section{II.1. Teorías absolutas}

Las teorías absolutas se encuentran desvinculadas de sus efectos sociales. Justifican la pena en orden a valores absolutos como la justicia, siendo irrelevante cualquier utilidad práctica de aquella ${ }^{18}$. La pena es vista como una reacción al delito cometido y será justa en la medida en que se encuentre una igualdad perfecta entre el mal que el delincuente realizó y el que se le impuso (retribución por el mal causado). Así, la pena tendrá un efecto de expiación, por lo que deberá cumplirse en su totalidad y magnitud, de modo que, luego de purgada la condena, el penado haya saneado íntegramente el estado de impureza que lo aquejaba $^{19}$. El problema de esta postura es que, en la medida en que el

15 BAURMANN, Michael. Ob. cit., pp. 185-186.

16 Demetrio CRespo, Eduardo. Fines de la pena e individualización judicial de la pena. Salamanca: Universidad Salamanca, 1999, pp. 56-57.

17 lbíd., p. 57.

18 Roxin, Claus. Nuevas formulaciones. Ob. cit., p. 212.

19 En esta línea, BuRdese. Manual de derecho público romano. A. Martínez Sarrión (trad.). Barcelona, 1972, pp. 297, 301-302. Citado por López Barja de Quiroga, Jacobo. Derecho penal. Parte general. Tomo III. Lima: Gaceta Jurídica, 2004, p. 26.

FUNCIÓN

CONSTITUCIONAL

ASIGNADA A LA

PENA:

BASES PARA UN

PLAN DE POLÍTICA

CRIMINAL

CONSTITUTIONAL

FUNCTION

ASSIGNED TO THE

PENALTY: BASES

FOR A CRIMINAL

POLICY PLAN 
proceso de expiación es interno, resulta imposible verificarlo de manera objetiva. Así, el esquema de determinación del marco legal de la pena, bajo esta postura, se centra en una pena tasada o exacta, acorde con la culpabilidad del sujeto.

Entre las teorías absolutas se encuentran la teoría de la retribución moral de Kant, la teoría de la retribución jurídica de Hegel y la teoría de la retribución divina. Para Kant, la pena no tiene ni debe tener utilidad alguna sino que debe estar justificada en sí misma: la pena no es un instrumento para la consecución de un bien, pues la dignidad del hombre impide que sea usada como un medio para fines que le son ajenos ${ }^{20}$.

Así, la pena debe existir incluso aunque la sociedad y el Estado se disuelvan, con el fin de «que cada cual sufra lo que sus hechos merecen ${ }^{21}$. Hegel parte de la idea de la equivalencia entre el delito y la pena, de modo que el delito es la negación del derecho expresada libremente por el hombre, mientras que la pena es el mecanismo para el restablecimiento del derecho a partir de la vulneración de la voluntad del penado ${ }^{22}$. La retribución divina, que encuentra dentro de sus seguidores a santo Tomás, ve en la justicia un mandamiento de Dios, por tanto la imposición de la pena sería la «ejecución sustitutoria de las funciones de juez de Dios» ${ }^{23}$.

Para estas posturas retribucionistas, en la medida en que la expiación es la justificación para la imposición de la pena, el penado tendría que cumplirla en su totalidad para purificarse, lo que implicaría un sistema carente de beneficios penitenciarios, mecanismos como el dos por uno, condonaciones por buena conducta, indultos, beneficios por colaboración eficaz, entre otros. Incluso puede aceptar la pena de muerte. Asimismo, la pena dependerá de la acción realizada por el penado y no dar cabida a la multa como sanción frente a una falta menor, dado que esto último legitimaría a quienes tienen dinero a realizar actos ilícitos.

Como resulta obvio, según el postulado constitucional vigente en el Perú este no es el fin de la pena en nuestro ordenamiento jurídico, máxime cuando la mera retribución trastoca la dignidad del ser humano, en tanto en sí misma no genera ningún aporte o beneficio ni para la sociedad ni para el autor del delito.

20 Demetrio Crespo, Eduardo. Ob. cit., p. 58.

21 Citando la obra de Kant (Metafísica de las costumbres), Roxin, Claus. Derecho penal. Parte general. Tomo I. Fundamentos. La estructura de la teoría del delito. Traducción de la segunda edición por Diego Manuel Luzón Peña, Miguel Díaz y García Conlledo y Javier Vicente Remesal. Madrid: Civitas, 1997, pp. 82-83.

22 Al respecto ver ibíd., p. 83 y Demetrio Crespo, Eduardo. Ob. cit., pp. 59-60.

23 Roxin, Claus. Derecho penal. Parte general. Ob. cit., p. 83. 


\section{II.2. Teorías relativas}

Las teorías relativas, dentro de las que se encuentran la prevención general y la prevención especial, buscan conseguir con la pena fines sociales (la pena no tiene un fin en sí misma, sino que a través de ella se alcanza un fin ulterior), ya sea influyendo en el penado (prevención especial) o en la comunidad (prevención general), para evitar la repetición de la conducta desvalorada o la producción de nuevos ilícitos ${ }^{24}$.

\section{II.2.2. La prevención especial}

Para esta teoría, la pena debe actuar sobre el penado en tanto su misión es intimidarlo para que desista de cometer nuevos ilícitos ${ }^{25}$, preservar la reincidencia a través de su corrección ${ }^{26}$ y proteger a la sociedad frente a los sujetos no susceptibles de resocialización ${ }^{27}$. Técnicamente, la corrección se denomina «resocialización»; bajo esta teoría, el penado debe ser capaz de reinsertarse a la sociedad (reeducarse) y de vivir en ella sin cometer delitos. Así, la pena se sustituye por un «tratamiento individualizado».

Sustentan esta teoría los postulados de Von Liszt, para quien «la pena correcta, o sea, la pena justa, es la pena necesaria. Justicia en derecho penal quiere decir observancia de la medida de la pena requerida por la idea del fin ${ }^{28}$. Von Liszt no era completamente ajeno a los postulados retribucionistas; para él, la pena era prevención mediante represión.

Saltan a la vista las ventajas que trae esta teoría respecto de la retribucionista, en tanto busca la protección de la sociedad y a la vez la tutela del penado, contribuyendo a su reintegración ${ }^{29}$. Sin embargo, debe tomarse en cuenta que, en la medida en que su finalidad es la resocialización del penado, un diseño legislativo que únicamente la tome en cuenta como sustento de la pena implicaría la introducción de una pena de duración indeterminada (hasta que el penado haya logrado resocializarse). Desde esta óptica, en algunos casos la pena carecería de sentido y no podría cumplir con la misión impuesta (cuando no sea necesaria una resocialización del penado) $)^{30}$. Por estas razones, una aplicación que se pretenda dar a esta teoría dentro de nuestro diseño

24 Ver: Roxin, Claus. Nuevas formulaciones. Ob. cit., p. 212; López Barja de Quiroga, Jacobo. Derecho penal. Parte general. Tomo IV. Madrid-Barcelona: Marcial Pons, 2002, pp. 34 y ss.

25 ZUGaLdía ESPINAR, José M. Derecho penal. Parte general. Valencia: Tirant Lo Blanch, 2002, p. 63.

26 Un mayor desarrollo sobre la teoría de la prevención especial, la encontramos en Roxin, Claus. Derecho penal. Parte general. Ob. cit., pp. 85 y ss.

27 DEMETRIO CRESPO, Eduardo. Ob. cit., p. 64. Este autor distingue entre prevención especial positiva, mediante la que se pretende que el autor no delinca más en el futuro, y prevención especial negativa, mediante la que se busca evitar la peligrosidad del autor mediante su inocuización.

28 Von LISzT, Frank. La idea de fin en el derecho penal. Monografías Jurídicas $\mathrm{N}^{\circ} 40$. Santa Fe de Bogotá: Temis, 1998, p. 56.

29 Lo que Roxin denomina "entrenamiento social y tratamiento de ayuda». RoxIN, Claus. Derecho penal. Parte general. Ob. cit., p. 87.

30 Estas son algunas de las críticas sostenidas por la doctrina en torno a la prevención especial como fin ulterior de la pena. Por todos, ver RoxIN, Claus. Derecho penal. Parte general. Ob. cit., pp. 87-89 y Demetrio Crespo, Eduardo. Ob. cit., p. 65.

FUNCIÓN

CONSTITUCIONAL

ASIGNADA A LA

PENA:

BASES PARA UN

PLAN DE POLÍTICA

CRIMINAL

CONSTITUTIONAL

FUNCTION

ASSIGNED TO THE

PENALTY: BASES

FOR A CRIMINAL

POLICY PLAN 
constitucional no puede dejar de lado principios limitadores del ius puniendi como los de legalidad, culpabilidad y proporcionalidad, entre otros $^{31}$.

Sin embargo, el problema central y el punto débil de esta teoría en una sociedad como la peruana se resume en las interrogantes formuladas por Cascajo Castro: «iQué significa exactamente la resocialización si la sociedad a la que se supone que los delincuentes van a regresar no existe? ¿Para qué se va a «socializar» a un joven si es claro que regresará a un hogar destrozado en un barrio marginal, sin oportunidad de un puesto de trabajo y con todos sus amigos y compinches básicamente en la misma situación?» ${ }^{32}$.

Estas preguntas, lamentablemente, no encuentran respuesta en el Perú, dado que la debilidad de las instituciones es la premisa que sustenta el día a día. Así, icómo es posible resocializar a un funcionario público que ha defraudado a la administración de justicia y hacerle interiorizar la importancia de esta institución, cuando esta se encuentra públicamente desacreditada?.

Estas observaciones nos hacen ver que, per se, este postulado resocializador es difícil de constatar en una sociedad como la nuestra, razón por la cual tanto los legisladores como los operadores del derecho y los propios ciudadanos debemos generar bases sólidas que faciliten la consecución de tal fin, máxime cuando el diseño de Estado constitucional así lo exige ${ }^{33}$ y 34 .

No obstante lo expuesto, las interrogantes planteadas no significan que no se deba apuntar a que la pena cumpla una función resocializadora: para los gobernantes peruanos debe ser premisa esencial de trabajo propiciar las condiciones que permitan fortalecer las instituciones y viabilizar la función resocializadora de la pena.

De lo expuesto se deduce que el fin preventivo especial de la pena supone unordenamientoen elquela resocialización del penadosea el fundamento

31 Con relación al planteamiento de un programa penal constitucional, ver GARCíA RIVAS, Nicolás. El poder punitivo en el Estado democrático. Cuenca: Universidad de Castilla - La Mancha, 1996, pp. 43 y ss.

32 CASCAJO CASTRO, José Luis. Ob. cit., p. 262.

33 Soy de la opinión de que una pregunta previa a responder, pero que excede los alcances y objetivos de este trabajo, es si realmente la realidad peruana y la evolución histórica responden a un modelo de Estado social y democrático de derecho, o si la introducción de este modelo simplemente constituye una fiel copia de otras realidades.

34 Ahora, si bien nuestra Constitución recoge como fin de la pena la resocialización, rehabilitación y reeducación del penado, resulta importante señalar que es innegable la vinculación existente entre el fin preventivo especial y la naturaleza retributiva de la pena. Al respecto, Ferrajoli señala: «la pena ejerce una función preventiva o intimidatoria sobre todo si se inflige al que la ha "merecido"» [...]. La garantía del carácter retributivo de la pena —en virtud de la cual nadie puede ser castigado más que por lo que ha hecho (y no por lo que es) - sirve precisamente para excluir al margen de cualquier posible finalidad preventiva o de cualquier otro modo utilitarista, el castigo del inocente aun cuando se le considere de por sí malvado, desviado, peligroso, sospechoso o proclive al delito, etc.». En FerRAJoli, Luigi. Derecho y razón. Ob. cit., pp. 368-369. 
central, de modo que se incluyan: beneficios penitenciarios que apunten a la consecución de este fin, cárceles adecuadas con programas de reincorporación de los presos, tratamientos resocializadores, descuentos de pena, leyes de colaboración eficaz, entre otros. Sin embargo, no debe olvidarse que, en la medida en que se apunta a la resocialización, los métodos usados para ello implicarán la imposición coactiva de ciertos valores a un grupo social que no los comparte. Por tanto, esta teoría debe compatibilizarse con los otros principios constitucionales que limitan la actuación del derecho penal ${ }^{35}$, en especial con el principio de mínima intervención.

Pese a las críticas que puedan formularse contra esta teoría, no puede dejar de considerarse a la resocialización como un objetivo al que no se puede renunciar y que debe ser de responsabilidad del Estado. En caso contrario, nuestras cárceles solo servirían para generar y crear delincuentes que luego, al ser devueltos a la sociedad, expresarían y volcarían toda su violencia en ella. En otras palabras, de cara a la repercusión social, no resulta rentable para la sociedad olvidarse de la finalidad preventiva especial de la pena, máxime en una sociedad como la peruana en la que, por el contrario, se promueve una «nueva forma de violencia» al recurrirse como única alternativa, adoptada por los legisladores en la solución de los conflictos sociales, a la criminalización excesiva de conductas irrelevantes para el derecho penal y al aumento indiscriminado de penas.

\section{II.2.2. La prevención general}

Esta teoría sostiene que el fin ulterior de la pena se encuentra en su influencia en la sociedad, de modo que la pena impuesta al penado sirva de ejemplo para evitar la comisión de delitos. Encontramos en su interior dos aspectos: uno negativo, planteado por Feuerbach a través de su teoría de la coacción psicológica, y otro positivo, que busca incentivar los valores normativos existentes en el ordenamiento jurídico.

Para la prevención general negativa, el centro de la pena es la intimidación, la que opera coaccionando a los miembros de la sociedad con el fin de que estos, luego de observar las consecuencias negativas de sus actos, se abstengan de cometer delitos ${ }^{36}$; es decir, se usa al penado como instrumento para evitar la comisión de futuros ilícitos penales ${ }^{37}$. Sin embargo, la mera aplicación de la pena sobre la base de su finalidad preventivo-general tendría que llevarnos a la

35 Ahondando en las críticas a la prevención especial: LóPEZ BARJA DE QUIROGA, Jacobo. Derecho penal. Parte general. Tomo IV. Ob. cit., pp. 40-41.

36 Feuerbach considera que el hombre es un ser racional capaz de calcular las consecuencias negativas de la pena frente a la comisión de un ilícito penal. Al respecto, ver Roxin, Claus. Derecho penal. Parte general. Ob. cit., pp. 89-91 y DemetRIO CRESPO, Eduardo. Ob. cit., p. 101.

37 El precedente de esta teoría se encuentra en Platón y, con posterioridad, en Beccaria y Bentham. Al respecto, ver García Rivas, Nicolás. El poder punitivo. Ob. cit., pp. 32-33.

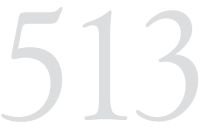

FUNCIÓN

CONSTITUCIONAL

ASIGNADA A LA

PENA:

BASES PARA UN

PLAN DE POLÍTICA

CRIMINAL

CONSTITUTIONAL

FUNCTION

ASSIGNED TO THE

PENALTY: BASES

FOR A CRIMINAL

POLICY PLAN 
imposición de penas lo suficientemente altas de modo que sirvan para la intimidación (generando terror penal en los ciudadanos ${ }^{38}$ ), junto con la eliminación de beneficios penitenciarios, leyes de colaboración eficaz, e incluso la introducción de la pena de muerte. Estas medidas claramente vulnerarían el modelo de Estado regulado en la Constitución peruana, por lo que no se consideran una opción a seguir.

Por otro lado, resulta necesario señalar que la imposición de penas graves no otorga ninguna seguridad de éxito a efectos de la intimidación -incluso la pena necesaria para conseguir este objetivo es inciertay genera incentivos para los delitos de ideología. Así, por ejemplo, en países como Brasil, donde las penas establecidas son bastante altas, no se ha acreditado una reducción del nivel de delincuencia o reincidencia de delitos $^{39}$. Por ello, al igual que en el caso de la teoría preventivo-especial, «el rendimiento preventivo-general de la norma penal no puede observarse al margen del resto de los mecanismos de control social $»^{40}$.

Según la teoría de la prevención general positiva, la pena cumple tres finalidades o efectos: el autoaprendizaje a partir de la relación que existe entre el comportamiento infractor de la norma y el deber de asumir las consecuencias derivadas, la confianza en la aplicación del derecho frente al quebrantamiento de una norma, y la pacificación que se genera al tranquilizar la conciencia jurídica en general, luego del restablecimiento del derecho ${ }^{41}$. En tal sentido, la imposición de la pena encuentra su razón de ser en la reafirmación de la norma que se vio vulnerada por una conducta contraria a derecho. Algunos autores ${ }^{42}$ ubican dentro de esta teoría al profesor Günther Jakobs, quien concibe al delito como «la desautorización de la norma o falta de fidelidad al ordenamiento jurídico actuado ${ }^{43}$. Sin embargo, esta ubicación debe ser cuidadosamente analizada, en tanto Jakobs ha señalado que, si bien se puede vincular la pena a «la esperanza de que se mantenga o solidifique la fidelidad

38 LÓPEZ BARJA DE QUIROGA, Jacobo. Derecho penal. Parte general. Tomo IV. Ob. cit., p. 36.

39 ZAFFARONI, Eugenio Raúl. Ponencia brindada en el encuentro internacional «La experiencia del penitenciarismo contemporáneo: aportes y experiencias", celebrado los días 26 y 27 de julio de 1993 en México, bajo la coordinación de la Dirección General de Reclusorios y Centros de Readaptación Social del Departamento del Distrito Federal y la II Asamblea de Representantes del Distrito Federal. También ver ZAFFARONI, Eugenio Raúl y Nilo BATISTA. Direito penal brasileiro. Tomo I. Río de Janeiro: Revan, 2003, p. 231.

40 Resumiendo lo expuesto por Hassemer, ver GARCíA RIVAS, Nicolás. El poder punitivo. Ob. cit., p. 34. 41 RoxIn, Claus. Derecho penal. Parte general. Ob. cit., p. 91.

42 LÓPEZ BARJA DE QUIROGA, Jacobo. Derecho penal. Parte general. Tomo I. Ob. cit., p. 23; LóPEZ BARJA DE QUIROGA, Jacobo. Derecho penal. Parte general. Tomo IV. Ob. cit., p. 46; RoxIN, Claus. Derecho penal. Parte general. Ob. cit., 2000, p. 92. Estos autores ubican a Jakobs como partidario del fin pacificador, al que denomina prevención integradora.

43 PARMA, Carlos. El pensamiento de Günther Jakobs. El derecho penal del siglo XXI. Argentina: Ediciones Jurídicas Cuyo, 2001, pp. 49-50. En la misma línea, Beloff señala que: «[...] para Jakobs, la función de la pena consiste en confirmar la validez de la norma pensada como modelo de orientación social. El castigo representa la contradicción de la negación de la norma y por su remedio se pretende fortalecer la estabilidad social y la fidelidad al derecho". En Mary Beloff. Determinación judicial de la pena. Buenos Aires: Editores del Puerto, 1993, p. 63. 
al ordenamiento jurídico», la pena significa algo con independencia de estas consecuencias: «significa una autocomprobación» ${ }^{44}$.

Tras esta concepción de la pena, no se concibe al derecho penal como protector de bienes jurídicos sino como un instrumento de estabilización social $^{45}$, de modo que la pena «es una muestra de la vigencia de la norma a costa de un responsable» ${ }^{46}$ y la que permite mantener a la norma como «modelo de orientación para los contactos sociales» ${ }^{47}$. No comparto esta concepción por considerar que el derecho penal tiene como función tutelar bienes jurídicos y no mantener la vigencia de instituciones, más aun cuando estas ni siquiera se encuentran definidas ni consolidadas en el Perú y presentan serios problemas de legitimidad.

Una aplicación práctica de esta teoría, en la medida en que el individuo es valorado únicamente por el cumplimiento de un rol funcional en relación con la totalidad del sistema social, nos llevaría a afirmar que la cárcel es capaz de re-crear determinados roles en el individuo que, a partir de su salida de esta, estaría listo para desempeñar, respetando las instituciones y contribuyendo con la creación del sistema. Ello difícilmente podría pensarse en una realidad como la peruana.

\section{II.2.3. Teorías de la unión}

Las teorías de la unión constituyen una postura ecléctica que recoge postulados retribucionistas (noción de la pena justa - teorías absolutas), así como fines preventivos en función de la utilidad de la pena (teorías relativas). En tal sentido, «solo una pena justa adecuada a la culpabilidad disuade y educa en un sentido social-pedagógico» ${ }^{48}$. Segun el énfasis que se otorgue a estos dos elementos, la doctrina distingue entre la teoría aditiva de la unión y la teoría dialéctica de la unión propuesta por Claus Roxin ${ }^{49}$. La primera suma las teorías absolutas y preventivas, priorizando el aspecto retributivo sobre la utilidad de la pena, pero sin dejar a esta última de lado. La utilidad de la pena se encuentra en los márgenes de la pena justa, de modo que el castigo presupone la culpabilidad de la persona, producto de un mal uso de su libertad ${ }^{50}$. A esta postura le son aplicables las críticas formuladas a las teorías absolutas y preventivas (las que, además, tienen finalidades

44 JAKOBS, Günther. Sociedad, norma y persona en una teoría de un derecho penal funcional. Manuel Cancio Meliá y Bernardo Feijóo Sánchez (trads.). Madrid: Civitas, 1996, pp. 18-19.

45 LÓPEZ BARJA DE QUIROGA, Jacobo. Derecho penal. Parte general. Ob. cit., p. 138.

46 JAKOBS, Günther. Derecho penal. Parte general. Fundamentos y teoría de la imputación. Joaquín Cuello Contreras y José Luis Serrano Gonzales de Murillo (trads.). Madrid: Marcial Pons, 1995, p. 9. Continúa diciendo este autor: «De ahí surge un mal, pero la pena no ha cumplido ya su cometido con tal efecto, sino solo con la estabilización de la norma lesionada».

47 lbíd., p. 14.

48 JESCHECK, Hans-Heinrich y Thomas WEIGEND. Tratado de derecho penal. Parte general. Miguel Olmedo Cardenete (trad.). Quinta edición. Granda: Comares, 2002, p. 81.

49 Roxin, Claus. Derecho penal. Parte general. Ob. cit., pp. 95 y ss.

50 LóPEZ BARJA DE QUIROGA, Jacobo. Derecho penal. Parte general. Tomo IV. Ob. cit., p. 42.

\section{FUNCIÓN}

CONSTITUCIONAL

ASIgNADA A LA

PENA:

BASES PARA UN

PLAN DE POLÍTICA

CRIMINAL

CONSTITUTIONAL

FUNCTION

ASSIGNED TO THE

PENALTY: BASES

FOR A CRIMINAL

POLICY PLAN 
contradictorias). Se resaltan las críticas expuestas contra la retribución, en tanto su aplicación práctica contradice el modelo de Estado establecido en la Constitución peruana. La segunda no concibe la pena sin que esta cumpla una utilidad, y dicha utilidad a la vez se encuentra limitada por la pena justa, de modo que se apunte a un equilibrio en el que los diferentes fines de la pena cumplan un rol recíproco. Así, «la culpabilidad no será el fundamento de la pena, sino que será el límite de la pena ${ }^{51}$. Roxin descarta las teorías absolutas por ir en contra del modelo de Estado social y democrático de derecho, rescatando las teorías preventivas: «El punto de partida de toda teoría hoy defendible debe basarse en el entendimiento de que el fin de la pena solo puede ser de tipo preventivo ${ }^{52}$. En tal sentido, se priorizará el fin preventivo general o preventivo especial en función de la etapa de determinación de la pena en la que nos encontremos:

- En la etapa legislativa, en la que el legislador pretende intimidar a los ciudadanos y disuadirlos de realizar conductas que causen un daño social, la pena deberá cumplir una función de prevención general, pero que tome como referente a la prevención especial (en caso contrario, el legislador podría regular penas de más de cuarenta años para hechos que no revierten tanto daño social).

- Enlaetapajudicial, en la medida en que existe una individualización de la pena en cada caso concreto, con un enfoque en el individuo que busca ser resocializado, debe primar la prevención especial.

- Este mismo fin debe primar en la etapa de ejecución, en tanto siempre deben tomarse en cuenta las posibilidades de resocialización del delincuente; por ello, no pueden regularse beneficios penitenciarios que solo se encuentren dirigidos a un grupo determinado de personas o de delitos, ya que ello implicaría pensar en el impacto en la sociedad y no en la resocialización del individuo.

De lo expuesto se deduce que, en tanto la pena cumple, en el modelo de Estado social y democrático de derecho que regula la Constitución peruana, una función resocializadora, rehabilitadora y educativa inmersa en los contornos de la prevención especial y general, la teoría acorde es la propuesta por Roxin. Sin embargo, debe precisarse que estos fines de la pena deben ir de la mano con los límites que imponen los principios limitadores del ius puniendi, como el de proporcionalidad, culpabilidad, mínima intervención, entre otros ${ }^{53}$. Ahora bien, esta función que ha 
sido asignada constitucionalmente a la pena en el Estado peruano debe estar presente en todos los niveles de determinación de aquella, lo que será objeto de reflexión en el presente trabajo.

En tal sentido, como parte del equilibrio entre el legalismo y el arbitrio judicial $^{54}$, la ley peruana fija límites máximos y mínimos dentro de los cuales el juez deberá determinar la pena a imponer en cada caso concreto, con el fin de que esta sea luego ejecutada. En tal sentido, se puede distinguir entre la determinación legal de la pena (conminación), la individualización judicial de la pena (imposición), y la determinación administrativa de la pena (ejecución penitenciaria). Esta última ha de ser «regulada legalmente y controlada judicialmente» ${ }^{55}$. En estas tres etapas resulta indispensable tomar en cuenta los postulados del modelo de Estado diseñado por la Constitución peruana, pues esta delimita los fines y funciones que la pena ha de cumplir en nuestro ordenamiento jurídico. En los próximos apartados se analizará si eso se condice con lo regulado en las normas de derecho interno y con la aplicación que los operadores del derecho otorgan a aquellas, con la finalidad se sentar ciertas bases para una reforma integral de la pena en el Perú.

\section{DETERMINACIÓN LEGAL DE LA PENA: PENA ABSTRACTA}

La determinación legal de la pena alude a la determinación en abstracto hecha por el legislador del marco legal a imponer frente a la lesión o puesta en peligro de un bien jurídico protegido por el derecho penal ${ }^{56}$. Para tal efecto, cobra importancia lo dispuesto por los principios de exclusiva protección de bienes jurídicos y lesividad ${ }^{57}$ que limitan el ius puniendi.

En el marco de un Estado social y democrático de derecho, el legislador deberá tomar en cuenta de modo abstracto aquellas circunstancias que fundamentan el ilícito penal, como el modo y forma de realización

54 Al respecto, ver ibíd., pp. 700 y ss.

55 lbíd., p. 701. Respecto de la distinción entre determinación legal de la pena e individualización judicial de la pena, ver DeMETRIO CRESPO, Eduardo. Ob. cit., pp. 41-44. Este mismo autor distingue entre individualización de la pena en sentido estricto e individualización de la pena en sentido amplio. También ver GARcía ARÁN, Mercedes. Los criterios de determinación de la pena en el derecho español. Barcelona: Edicions de la Universitat de Barcelona, 1982, p. 65.

56 Es de señalar que existen varios sistemas de determinación de la pena, entre los que tenemos: (i) penas absolutas o catalogadas, donde el legislador establece previamente las sanciones específicas a aplicar por la comisión de determinado delito; (ii) penas indeterminadas, en las que la ley no determina la pena a aplicar, ni fija límites a la voluntad del juzgador, sino que permite a este establecer la sanción penal adecuada para cada caso concreto; (iii) penas relativas o parcialmente determinadas, en donde el legislador determina previamente límites máximos y mínimos de la pena que podrá ser impuesta por el juez, de acuerdo con el ilícito perpetrado; es dentro de este último sistema que se ubica el modelo legislativo peruano. Respecto de los sistemas descritos, ver ORTS BERENGUER, Enrique. "El papel de las circunstancias modificativas de la responsabilidad de la pena". II Congreso Internacional de Derecho Penal - Consecuencias Jurídicas del Delito. Lima: ARA, 1997, pp. 243 y ss.

57 Artículo IV del Título Preliminar del Código Penal peruano: «La pena, necesariamente, precisa de la lesión o puesta en peligro de bienes jurídicos tutelados por la ley».

FUNCIÓN

CONSTITUCIONAL

ASIGNADA A LA

PENA:

BASES PARA UN

PLAN DE POLÍTICA

CRIMINAL

CONSTITUTIONAL

FUNCTION

ASSIGNED TO THE

PENALTY: BASES

FOR A CRIMINAL

POLICY PLAN 
del delito, los agravantes y atenuantes que podrían concurrir y otros elementos que puedan servir para llevarlo a establecer un marco legal en el que la pena máxima corresponda a las manifestaciones más graves del delito, y la mínima, a las manifestaciones más leves ${ }^{58}$. Así, por ejemplo, la modalidad dolosa de un delito recibe más pena que su modalidad culposa, la lesión de un bien jurídico es más desvalorada que su simple puesta en peligro, la lesión realizada con mediación de violencia es más grave que la lesión en la que no se utiliza dicho medio, etc. Así, el legislador debe establecer un marco legal con máximos y mínimos que deben ser acordes con los fines preventivos y reeducadores de la pena que impone el modelo de Estado recogido en la Constitución peruana. Por ello, resulta inconcebible con este objetivo la imposición de una pena única para sancionar una infracción (pena tasada).

En las siguientes líneas se efectuará una descripción y análisis de lo establecido en el aspecto normativo por nuestro legislador en torno a la pena, tomando en cuenta lo ya señalado respecto de la función constitucional que aquella debe cumplir.

\section{III.1. Pena mínima y pena máxima establecidas por el legislador peruano}

El artículo 29 del Código Penal peruano establece que la pena privativa de libertad puede ser temporal o de cadena perpetua.

- En el caso de la pena temporal, señala que la pena mínima es de dos días, mientras que la pena máxima es de 35 años. En relación con la pena mínima, en mi opinión esta no se condice con los fines preventivos que la pena debe cumplir en un Estado social y democrático de derecho como el peruano. Una pena corta constituye un claro ejemplo de un retribucionismo puro y duro, en tanto sería absurdo pensar que una persona que ingrese a prisión por dos días vaya a ser capaz de resocializarse. Muy por el contrario, esos dos días de cárcel solo generarían un efecto pernicioso que no se condice con los fines preventivos de la pena, lo que constituye un problema de cara al marco constitucional descrito en los apartados anteriores. Con relación a la pena temporal máxima de 35 años se aplican similares críticas a las efectuadas para la pena mínima, en tanto es muy cuestionable que una persona que permanezca en prisión por 35 años alcance la resocialización: las penas excesivamente cortas y largas son meramente retributivas y no ostentan ninguna finalidad resocializadora, lo que no se condice con el modelo de Estado constitucional peruano y debe ser objeto de un replanteamiento 
por parte del legislador, a efectos de ser coherente con los lineamientos constitucionales.

- Con relación a la pena de cadena perpetua, resulta evidente que esta no cumple fin resocializador alguno, sino que constituye una mera muestra de puro retribucionismo, lo que contraviene claramente lo establecido por la Constitución. No obstante, conforme se aprecia en nuestro Código Penal, existen diversos delitos que prevén este tipo de pena. Así, tenemos los casos de feminicidio en los que concurran dos o más agravantes (artículo 108-B último párrafo), el secuestro de menor de edad o de mayor de 70 años (artículo 152), la violación sexual de un menor de 10 años (artículo 173.1), el robo agravado en el que el que el sujeto activo es miembro de una banda (artículo 189, último párrafo), la sustracción o arrebato de arma de fuego en la que se produce una lesión grave o muerte de un tercero (artículo 279-B), entre otros. Una reforma coherente con las funciones preventivas que se asigna a la pena en la Constitución peruana debería eliminar la cadena perpetua en tanto no permite resocialización alguna, estableciendo siempre la posibilidad futura de una revisión de la sanción penal.

\section{III.2. Clases de penas reguladas por el legislador}

El artículo 28 del Código Penal peruano regula cuatro clases de penas: la privativa de libertad, la restrictiva de libertad, la limitativa de derechos y la multa.

Conforme se ha señalado en el apartado anterior, la pena privativa de libertad puede ser temporal (mínima de dos días y máxima de 35 años) o de cadena perpetua. Adicionalmente, el legislador peruano ha introducido, dentro de la sección correspondiente a la pena privativa de libertad, la de vigilancia electrónica personal, cuya ejecución se realiza en el domicilio o lugar que señale el condenado. En estos casos, el juez fija todas las reglas que considera necesarias para la idoneidad de la medida y el cómputo de su aplicación es a razón de un día de privación de libertad por un día de vigilancia electrónica personal. Pueden acceder a este tipo de medidas los condenados que no hayan sido anteriormente sujetos de sentencia condenatoria por delito doloso, estableciéndose una prioridad en la norma penal59.

Si bien esta medida se encuentra más cercana a las funciones constitucionales de la pena (resocialización del individuo), presenta algunos problemas en torno a los supuestos de aplicación, los que

FUNCIÓN

CONSTITUCIONAL

ASIGNADA A LA

PENA:

BASES PARA UN

PLAN DE POLÍTICA

CRIMINAL

CONSTITUTIONAL

FUNCTION

ASSIGNED TO THE

PENALTY: BASES

FOR A CRIMINAL

POLICY PLAN 
a mi parecer se encuentran indebidamente restringidos al imposibilitar su aplicación a personas que hubieran sido condenadas por cualquier delito doloso. Así, por ejemplo, quien haya sido condenado por manejar en estado de ebriedad no podría solicitar la aplicación de esta medida.

Por otro lado, la expulsión del país (pena restrictiva de la libertad) se encuentra regulada en el artículo 30 del Código Penal peruano y es de aplicación a los extranjeros que hayan cumplido una pena privativa de libertad.

Las penas limitativas de derechos, conforme lo dispone el artículo 31 del Código Penal, son de tres tipos: prestación de servicios a la comunidad, limitación de días libres e inhabilitación. Las dos primeras se aplican de forma autónoma cuando están específicamente señaladas para cada delito, o como sustitutivas o alternativas de la libertad cuando la sanción sustituida, a criterio del juez, no sobrepase los cuatro años (artículo 32 del Código Penal).

Conforme establece el artículo 34 del mismo cuerpo legal, la pena de prestación de servicios a la comunidad obliga al condenado a trabajos gratuitos en entidades asistenciales, hospitalarias, escuelas, orfanatos, otras instituciones similares u obras públicas. Los servicios se asignan en función de las aptitudes del condenado y deben cumplirse en jornadas de diez horas semanales entre sábados y domingos (para no perjudicar la jornada normal de su trabajo habitual). Esta pena es susceptible de extenderse de 10 a 156 jornadas de servicios semanales.

La pena de limitación de días libres (artículo 35 del Código Penal) consiste en la obligación de permanecer los días sábados, domingos y feriados, por un mínimo de diez y un máximo de dieciséis horas en total por cada fin de semana, en un establecimiento organizado con fines educativos y sin las características de un centro carcelario. Este tipo se sanción se encuentra más acorde con los fines preventivos, pues el condenado incluso debe recibir orientación tendiente a su rehabilitación. La pena no puede extenderse de 10 a 156 jornadas de limitación semanales; no obstante, lamentablemente esta pena, regulada en la parte general del Código Penal, no es de las más utilizadas por el legislador a la hora de determinar el marco abstracto de la pena en los delitos ubicados en la parte especial, lo que no contribuye a la consecución de los fines que la Constitución asigna a la pena en el Perú.

La pena de inhabilitación (artículo 36 del Código) puede ser principal o accesoria. La primera se extiende de seis meses a cinco años (salvo en los casos en los que es definitiva), y la segunda se extiende por igual tiempo que la pena principal. Entre los supuestos contemplados para la inhabilitación, se tienen: la incapacidad para desempeñar un cargo público, la suspensión de derechos políticos, la incapacidad para ejercer 
profesión o industria, la incapacidad para ejercer la patria potestad, la suspensión o cancelación de la autorización para portar o hacer uso de armas de fuego, la suspensión o cancelación de la autorización para conducir vehículos, la incapacidad definitiva para ingresar al servicio docente para los condenados por terrorismo, violación sexual o tráfico de drogas, entre otros.

La pena de multa obliga al condenado a pagar al Estado una suma de dinero fijada en días multa (artículo 41 del Código Penal), efectuando el cálculo en función del ingreso promedio diario del condenado; se extiende desde los 10 hasta los 365 días multa y no puede ser menor del 25\% ni mayor del 50\% del ingreso diario del condenado cuando viva exclusivamente de su trabajo. Debe ser pagada dentro de los diez días de emitida la sentencia, salvo que el juez permita el pago en cuotas mensuales.

Como se aprecia, la parte general del Código Penal contempla gran diversidad de clases de pena, dentro de las que la pena privativa de libertad constituye la menos favorable de cara a los fines preventivos que la pena debe cumplir según el marco constitucional. Sin embargo el legislador, al momento de determinar el marco abstracto de la pena de los delitos de la Parte Especial, recurre con mayor frecuencia a la clase de pena que menos favorece a la resocialización; es decir, recurre a la pena privativa de libertad, lo que evidencia que el peruano es un código carcelario en el que se llega a absurdos, como el dejar elegir al juez (al momento de la individualización judicial de la pena concreta) entre imponer una pena privativa de libertad o una pena de multa. No es concebible una pena alternativa que permita elegir al juez entre multa o cárcel, en tanto es obvio que, a la luz de los criterios preventivos de la pena, se tendría siempre que elegir la primera. Este ejemplo refleja que las normas penales de derecho interno no son acordes con los fines preventivos que la Constitución otorga a la pena en el Perú, lo que debe ser tomado en cuenta para una reforma legislativa.

\section{III.3. Penas tomadas en cuenta por el legislador para la determinación del marco legal de la pena en los de- litos de la Parte Especial del Código Penal}

Como se observa en el Código Penal peruano, la pena privativa de libertad es la clase de pena que el legislador utiliza de forma más frecuente para la sanción de ilícitos. Existen las siguientes combinaciones de penas:

- Prisión, inhabilitación y días multa

- Prisión y días multa

- Prisión e inhabilitación 
- Prisión y prestación de servicio comunitario

- Solo prisión

- Prisión o días multa, más inhabilitación

- Prisión o prestación de servicio comunitario, más inhabilitación

- Prisión o días multa

- Prisión o prestación de servicio comunitario

- Prisión o limitación de días libres

- Días multa e inhabilitación

- Prestación de servicio comunitario e inhabilitación

- Solo días multa

- Solo inhabilitación

- Solo prestación de servicios comunitarios

- Solo limitación de días libres

- Prestación de servicios comunitarios o días multa

De las preferencias del legislador para la determinación de la pena abstracta se pueden deducir, entre varias, las siguientes conclusiones principales:

a) En algunos casos, los marcos mínimos y máximos utilizados por el legislador peruano son muy amplios, lo cual deja al juzgador un gran arbitrio para la determinación de la pena concreta. Esto puede apreciarse en el artículo 280, segundo párrafo del Código Penal, en que se sancionan los atentados contra los medios de transporte colectivo o de comunicación con un marco de pena

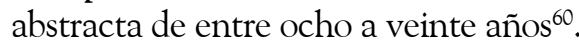

b) Existen delitos, como el artículo 241 del Código Penal peruano, que son sancionados con una pena mínima de dos días de prisión, lo cual es absurdo de cara a los fines preventivos de la pena y la resocialización: no es posible socializar a una persona imponiéndole una pena de dos días, muy por el contrario, en estos casos, el ingreso a un penal probablemente sería totalmente pernicioso. En esta línea, resulta evidente que los delitos que se castigan con tan poca pena no ostentan la lesividad necesaria para que se castiguen con prisión; por ello, las penas cortas deben ser reemplazadas con otras previstas en la parte general del Código Penal, como es el caso de los días multas: el primer paso para un derecho penal mínimo

60 Lo mismo ocurre en España, donde la pena mínima es de seis meses (no permite la resocialización), operando las reformas penales de espaldas a las exigencias de la moderna política criminal. ZUGALDÍA ESPINAR, José Miguel. «Contrarreforma penal (el annus horribilis de 2003) y el anteproyecto de reforma del Código Penal de 2006». En Francisco Bueno Arús y otros (dirs.). Derecho penal y criminología como fundamento de la política criminal. Estudios en homenaje al profesor Alfonso Serrano Gómez. Madrid: Dykinson, 2006, p. 1353. 
es eliminar las penas cortas, en tanto una pena corta no cumplirá jamás con los cometidos de prevención de una pena en un Estado social y democrático de derecho.

c) Las modalidades culposas se sancionan con pena privativa de libertad, pero resulta absurdo que alguien que actuó por culpa requiera un penal para resocializarse, más aún cuando —como se ha señalado- algunos de estos delitos (como es el caso del artículo 229, segundo párrafo del Código Penal, que regula la modalidad culposa del delito de omisión de deberes de funcionarios públicos) se sancionan con una pena mínima de dos días y una pena máxima de dos años. Al regular esta clase de sanciones, el legislador contraviene los fines preventivos de la pena en un Estado constitucional como el peruano.

d) Es absurdo que el legislador regule penas alternativas como las de prisión o multa, prisión o prestación de servicio comunitario, prisión o limitación de días libres, ya que al permitir una elección por el juez evidencia que la prisión no es el mecanismo excepcional para la resocialización del individuo cuando siempre debe preferirse la cárcel como última posibilidad frente a la comisión de un delito. Las combinaciones de los diversos tipos de penas no hacen más que evidenciar que, al regular los delitos de la parte especial, el legislador peruano no tuvo en cuenta los fines preventivos que la Constitución otorga a la pena. Esto genera un contrasentido dentro del derecho interno en un Estado que se autodefine como social y democrático de derecho.

e) Se contravienen los postulados preventivos de la pena al regular conductas de forma simbólica, como es el caso del artículo 120 del Código Penal, que regula el aborto sentimental y eugenésico con un marco abstracto de pena de entre dos días y tres meses. Como resulta evidente, habida cuenta de lo establecido en el artículo 83 del mismo cuerpo legal: «[...] la acción penal prescribe, en todo caso, cuando el tiempo transcurrido sobrepasa en una mitad al plazo ordinario de prescripción (máximo de la pena)», este delito nunca podría llegar a sancionarse, ya que no existe proceso penal en el Perú que dure menos de cuatro meses y medio (plazo de prescripción extraordinaria). Así, este se convierte en un uso simbólico del derecho penal totalmente contrario al modelo social y democrático de Estado que regula la Constitución peruana ${ }^{61}$.

Lamentablemente, el legislador peruano no parece tener muy claro que el uso de la pena privativa de libertad debe ser excepcional y únicamente en los casos necesarios; ello se refleja en el hecho de que la

FUNCIÓN

CONSTITUCIONAL

ASIGNADA A LA

PENA:

BASES PARA UN

PLAN DE POLÍTICA

CRIMINAL

CONSTITUTIONAL

FUNCTION

ASSIGNED TO THE

PENALTY: BASES

FOR A CRIMINAL

POLICY PLAN 
mayoría de penas reguladas son privativas de libertad. En este aspecto, la introducción de la pena de vigilancia electrónica personal no resulta suficiente, pues no soluciona el problema de fondo: un ánimo carcelario del legislador que muchas veces se explica en cuestiones extrajurídicas (elecciones, réditos políticos, entre otras).

Resulta claro que existe una distorsión entre la pena abstracta y las técnicas legislativas utilizadas por el legislador peruano, pues en la práctica no se respeta la función que la Constitución peruana asigna a la sanción penal.

\section{INDIVIDUALIZACIÓN JUDICIAL DE LA PENA: PENA CONCRETA}

La individualización judicial de la pena alude a la pena impuesta por el juez, en cada caso concreto, dentro del marco legal (pena abstracta) establecido por el legislador. El arbitrio judicial requerido para la individualización de la pena no debe confundirse con la mera arbitrariedad para su imposición ${ }^{62}$. Así, el juez se encuentra en la obligación de tomar en cuenta las condiciones personales del autor, su participación en el hecho en concreto, la gravedad del hecho delictivo, entre otros, imponiendo la pena en función a las posibilidades reeducativas y de reinserción del penado a la sociedad.

Prueba de ello son las distintas instituciones creadas por el ordenamiento jurídico peruano, que permiten al juez valorar las finalidades preventivas de la pena en cada caso concreto, como la sustitución de la pena privativa de libertad, la suspensión de la ejecución de la pena, la desaparición de la condena, la reserva del fallo condenatorio, la exención de pena, la rehabilitación automática, etc. ${ }^{63}$, que serán objeto de análisis en los párrafos siguientes. Si bien estas instituciones permiten al juez hacer una valoración de cara de los fines preventivos de la pena en el caso concreto, considero que son insuficientes a la luz de la función constitucional de la pena y que, en la práctica, no funcionan de forma adecuada.

Así, mientras que en la determinación del marco legal de la pena el legislador analiza en un plano abstracto las posibles condiciones del autor, los grados de participación de los intervinientes en el hecho delictivo y los supuestos relacionados con la realización misma del tipo para determinar el mínimo y el máximo imponible, en la individualización judicial (pena concreta) el juez no analiza las circunstancias concurrentes 
en un plano abstracto sino que las valora en un plano tópico, tomando en cuenta las circunstancias específicas de cada caso $^{64}$.

Por esta razón, no puede perderse de vista la prohibición de una doble valoración, en tanto no es posible agravar dos veces la misma circunstancia: en la elección del tipo penal (determinación del marco legal de la pena) y en la elección de la pena a imponer en el caso en concreto (individualización judicial de la pena) ${ }^{65}$. Esto vulneraría el principio de ne bis in idem ${ }^{66}$, así como el principio de división de poderes propio de un Estado como el peruano ${ }^{67}$.

Pese a lo expuesto, la vinculación entre legalismo y arbitrio judicial no es muy pacífica: hay diferentes posturas para establecer la pena a imponer. Una primera postura retribucionista (teoría de la pena exacta o puntual) ${ }^{68}$ considera que la culpabilidad permite determinar el punto exacto que corresponde a lo merecido por el delincuente, considerando a la pena como compensación de la culpabilidad. Esta postura claramente contraviene los postulados de un Estado social y democrático de derecho, en tanto descarta cualquier fin preventivo de la sanción ${ }^{69}$.

Una segunda postura, también de corte retribucionista (teoría de la proporcionalidad con el hecho), tiende a objetivos de igualdad y justicia, planteando una proporcionalidad absoluta y una relativa. Esta última postula la equivalencia entre las penas de cara a diferentes delitos (si diversas personas realizan delitos equiparables, recibirán penas equiparables). Por el contrario, la proporcionalidad absoluta se refiere a la determinación proporcional de la pena de otros delitos que permitan fijar la del resto. Esta teoría no indica cuál es la pena inicial como variable de la que se parte para fijar la pena final y tampoco señala cuáles son los criterios que determinan la cantidad de necesidad de pena ${ }^{70}$.

64 Hay que reconocer que los criterios a seguir para la determinación del marco legal son distintos. Al respecto, ver JESCHECK, Hans-Heinrich y Thomas WEIGEND. Ob. cit., p. 941.

65 Al respecto ver Ziffer, Patricia S. Ob. cit., p. 107.

66 Este principio ha sido reconocido de modo expreso en el artículo III del Título Preliminar del Código Procesal Penal (decreto legislativo 957, publicado en El Peruano el 29 de julio de 2004 y vigente en algunos distritos judiciales del Perú. Posee una doble significación, al ser un principio material según el que nadie puede ser castigado dos veces por la misma infracción, y un principio procesal, en tanto nadie puede ser juzgado dos veces por los mismos hechos. Ver COBO DEL ROSAL, Manuel y Tomás S. VIVES ANTón. Derecho penal. Parte general. Quinta edición. Valencia: Tirant lo Blanch, 1999, p. 91.

67 Respecto de la necesidad de distinguir entre el rol que corresponde al legislador, del rol que corresponde al juez, ver ZIFFER, Patricia S. Ob. cit., pp. 109-110.

68 Esta teoría cuenta con versiones modificadas, como es el caso de la teoría de la proporcionalidad con el hecho, de las teorías neoclasicistas, o de la teoría del acto de gestación social impulsada por Eduard Dreher, quien por recurrir a confusos criterios como «la convicción jurídica de la población» termina planteando una pena correcta de corte retributivo. Ver DREHER, Eduard. Citado por Demetrio Crespo, Eduardo. Ob. cit., pp. 192-193.

69 Al respecto, ver MIR PUIG, Santiago. Derecho penal. Parte general. Ob. cit., p. 709; MAgaRiÑos, Mario. "Hacia un criterio para la determinación judicial de la pena». En Julio B.J. Maier (comp.). Determinación judicial de la pena. Buenos Aires: Editores del Puerto, 1993, p. 74.

70 Demetrio Crespo, Eduardo. Ob. cit., pp. 203-205.

FUNCIÓN

CONSTITUCIONAL

ASIGNADA A LA

PENA:

BASES PARA UN

PLAN DE POLÍTICA

CRIMINAL

CONSTITUTIONAL

FUNCTION

ASSIGNED TO THE

PENALTY: BASES

FOR A CRIMINAL

POLICY PLAN 
Una tercera postura (teoría del espacio de juego o del margen de la libertad) señala que la pena debe ser medida en función a la culpabilidad y no puede ser concretizada en un punto exacto, sino dentro de un marco de máximos y mínimos dentro del cual el juez ostenta un espacio de juego para graduar la pena, conforme con las necesidades preventivas de su imposición ${ }^{71}$. El problema con esta teoría es que la culpabilidad como medida para la determinación del marco máximo resulta vaga, imprecisa y abstracta para el objetivo de ir precisando hacia abajo la pena a imponer; es decir, no establece fronteras definidas sino solo límites flexibles.

Una cuarta postura (teoría del valor jerárquico del empleo) plantea dos niveles y tiene por objeto la simplificación del problema de las antinomias de los fines de la pena. Los dos niveles estriban en que, en el primero, el juez fija el peso del injusto culpable con el fin de establecer el quantum de la pena, de manera que las consideraciones preventivo-generales y preventivo-especiales se aplican en segundo lugar, en el modo de la imposición de la pena adecuada a la culpabilidad ${ }^{72}$.

Una versión parecida a la anterior la conforma la teoría del valor de la posición o del valor posicional, que asigna a la culpabilidad el rol de decidir por sí sola la duración de la pena, mientras que atribuye a la prevención el rol de orientar la decisión acerca de si hay que suspender o sustituir la pena por otra medida, aspecto este último en el que solo interesa la prevención especial ${ }^{73}$.

Si bien es cierto que las diversas teorías discurren en pretender un mejor manejo de las antinomias que presenta la individualización de la pena (prevención y culpabilidad, en sus dos versiones general y especial, tanto negativa como positiva), en el Perú, la dogmática de la individualización judicial de la pena se ha visto fijada por la dogmática del derecho penal, con lo que su desarrollo aún es incipiente. Lo mismo ocurre con los puntos de referencia para diferenciar qué variables se aplican en la fijación de la pena final: caso normal, culpabilidad individual, la ya mencionada convicción jurídica de la población, o de cómo considerar la presencia $\mathrm{o}$ ausencia de la reincidencia, o la dependencia toxicológica ${ }^{74}$. Este es un punto muy problemático para los jueces peruanos y una materia muy poco tocada en los cursos de derecho de las diferentes universidades del Perú.

Aun así, lo que resulta claro es que la gravedad de los delitos es valorada en función de la importancia de los bienes jurídicos y corresponde al

71 Ver MIR PUIG, Santiago. Derecho penal. Parte general. Ob. cit., p. 710; LÓPEZ BARJA DE QUIROGA, Jacobo. Derecho penal. Parte general, Tomo IV. Ob. cit., pp. 214-215.

72 Demetrio Crespo, Eduardo. Ob. cit., pp. 200-201.

73 Ver MIR PUIG, Santiago. Derecho penal. Parte general. Ob. cit., p. 710; MAGARIÑOS, Mario. Ob. cit., pp. 74-75.

74 Demetrio Crespo, Eduardo. Ob. cit., p. 213. 
legislador efectuar esta valoración cuando fija la pena abstracta para cada tipo penal. De allí que el juez no puede valorar a su libre arbitrio la gravedad del injusto perpetrado, dado que corresponde al legislador brindar al juez los márgenes para que este alcance la fijación de la pena final. Por esta razón, resulta indispensable un programa de política criminal en el ámbito legislativo que establezca los márgenes mínimos y máximos de pena, tomando en cuenta la función preventiva de aquella en un Estado de derecho como el que regula la Constitución peruana. La falta de coherencia en la determinación legislativa de las penas, como viene ocurriendo en el Perú, solo propiciará una falta de coherencia en la determinación de la pena en el caso concreto.

En otras palabras, el ordenamiento jurídico peruano no recoge ninguna de las teorías mencionadas en los párrafos previos y ni siquiera ha superado el diseño de normas coherentes y acordes con el fin preventivo de la pena regulado por la Constitución. El juzgador no ha tomado en cuenta que las normas de la Parte General se aplican al hecho punible previsto en las leyes especiales (artículo X del Título Preliminar del Código Penal peruano), teniendo como referencia que la sanción penal no puede sobrepasar la responsabilidad por el hecho (artículo VIII del mismo cuerpo normativo). Por ello, lo primero que debe hacerse es desarrollar en qué consiste esta responsabilidad por el hecho, así como si esta tiene a la pena máxima como la necesidad de pena para legitimarla o limitarla en función de la culpabilidad.

El juzgador peruano, salvo honrosas excepciones, se ha limitado a señalar y hacer referencia a un conjunto de artículos del Código Penal y Procesal Penal que no dan cuenta de cómo se ha racionalizado la fijación del quantum de la pena final (motivación de su imposición), haciendo al condenado imposible contradecir lo que no conoce y no aparece en la sentencia condenatoria. Todo esto no hace más que reflejar el poco garantismo del sistema y, con ello, la necesidad de que la pena abstracta y la pena concreta se encuentren acordes con los fines preventivos previstos por el texto constitucional.

En esta línea, dentro del marco normativo actual, las instituciones de las que puede valerse el juez para la determinación de la pena concreta y el cumplimiento de la misma son las siguientes:

\section{IV.1. Reserva del fallo condenatorio}

El artículo 62 del Código Penal regula lo que se denomina reserva del fallo condenatorio, consistente en una abstención del juzgador de dictar la parte resolutiva de la sentencia en la que estaría fijada la pena; así, el juez puede disponer la reserva del fallo condenatorio por un plazo de uno a tres años contados desde que la decisión adquiere la calidad de 
cosa juzgada, en los supuestos en los que la naturaleza, modalidad del hecho punible y personalidad del agente hagan prever que esta medida le impedirá cometer un nuevo delito, disponiendo el cumplimiento de ciertas reglas de conducta.

La reserva del fallo es dispuesta en los siguientes casos: (i) cuando el delito está sancionado con pena privativa de libertad no mayor de tres años o con multa; (ii) cuando la pena a imponerse no supere las noventa jornadas de prestación de servicios a la comunidad o de limitación de días libres, y (iii) cuando la pena a imponerse no supere los dos años de inhabilitación.

Esta abstención efectuada por el juez en nada le impedirá fijar las responsabilidades civiles que provengan del delito. La reserva del fallo se inscribirá en un registro especial que se encuentra a cargo del Poder Judicial, que es especial, confidencial y provisional y no permite, por ningún motivo, la expedición de certificados para fines distintos.Esta inscripción quedará sin efecto de forma automática una vez cumplido el período de prueba, lo que deberá ser verificado por el juez de origen (artículo 63 del Código Penal).

Entre las reglas de conducta que puede disponer el juez para que sean cumplidas por el procesado (las que son muy parecidas a las reglas de conducta impuestas para la suspensión de la ejecución de la condena) se encuentran: (i) prohibición de frecuentar determinados lugares; (ii) prohibición de ausentarse del lugar donde reside sin autorización del juez; (iii) comparecer mensualmente al juzgado, personal y obligatoriamente, para informar y justificar sus actividades; (iv) reparar los daños ocasionados por el delito, salvo que demuestre que esté imposibilitado de hacerlo; (v) que el agente no tenga en su poder objetos susceptibles de facilitar la realización de otro delito, y (vi) las demás reglas de conducta que el juez estime convenientes para la rehabilitación social del agente, siempre que no atente contra la dignidad del procesado (artículo 64 del Código Penal).

Conforme lo señala el artículo 65, en caso que el sujeto incumpliera con las reglas impuestas por razones atribuibles a su responsabilidad, el juez puede: (i) hacerle una severa advertencia; (ii) prorrogar el régimen de prueba sin exceder la mitad del plazo inicialmente fijado (en ningún caso la prórroga acumulada sobrepasará de tres años), o (iii) revocar el régimen de prueba. Adicionalmente, el juez deberá obligatoriamente revocar el régimen de prueba en los casos en los que el agente sea condenado, por un nuevo delito doloso, a una pena privativa de libertad superior a tres años. En caso de revocación se aplicará al sujeto la pena que le correspondía, mientras que si el sujeto cumple con el período de prueba, este se considerará como extinguido y el juzgamiento como no efectuado. 
En relación con la reserva del fallo condenatorio, resulta necesario precisar que este no es un mecanismo alternativo a la pena privativa de libertad sino un instrumento que el legislador regula y que debe ser interpretado de cara a los fines preventivos constitucionales de la pena; por tal razón, de cara a la resocialización y en el caso de delitos imprudentes o con una pena no grave, deberá aplicarse de forma preferente respecto de las otras figuras establecidas en el Código Penal (sustitución y suspensión de pena).

En igual línea se encuentra la exención de pena regulada en el artículo 68 del Código Penal, que supone que el juez pueda eximir de sanción en los casos en que el delito esté previsto en la ley con pena privativa de libertad no mayor de dos años o con pena limitativa de derechos o con multa, si la responsabilidad del agente fuere mínima. Al igual que la reserva del fallo condenatorio, esta figura no supone la imposición de una pena, por lo que debe preferirse respecto de la sustitución o suspensión de la pena privativa de libertad.

El problema es que a la fecha, en el Perú, los jueces no hacen prevalecer la reserva del fallo condenatorio o la exención de pena para los supuestos en los que se cumplen los requisitos establecidos en la parte general del Código Penal, lo que genera una distorsión de esta figura, sobre todo en los casos culposos, los que — como ya se ha mencionado- ni siquiera deberían de sancionarse con pena privativa de libertad, por carecer de objeto la resocialización de un sujeto que no necesariamente lo requiere. En tal sentido, para el caso de los delitos culposos deben preferirse estas dos opciones a la imposición o sustitución de una pena.

\section{IV.2. Sustitución de la pena privativa de libertad}

La sustitución implica el cambio de la pena de prisión por otra pena que haga percibir al condenado el daño de su acción, pero evitando la cárcel. En el Perú, al amparo del artículo 52 del Código Penal, se puede convertir o sustituir la pena privativa de libertad por las siguientes penas: multa, prestación de servicios a la comunidad, limitación de días libres y vigilancia electrónica personal. Sin embargo, el legislador establece ciertas diferencias en función de la duración de la pena privativa que sea impuesta al condenado. Así, tenemos:

- Las penas de prisión no mayores de dos años se pueden sustituir multas.

- Las penas de prisión no mayores a cuatro años se pueden sustituir por prestación de servicios a la comunidad o limitación de días libres, a razón de un día de prisión por un día de multa y de siete días de prisión por una jornada de prestación de servicios a la comunidad o por una jornada de limitación de días libres. 
- Las penas de prisión en general por la vigilancia electrónica personal, a razón de un día de prisión por un día de vigilancia electrónica personal.

Al respecto, cabe mencionar que el artículo 52 del Código Penal peruano establece que la sustitución de la pena puede ser dispuesta por el juez en los casos en los que no fuera procedente la condena condicional o la reserva del fallo condenatorio; no obstante ello — como se verá en el siguiente punto-, deberían darse más facilidades para la sustitución que para la suspensión de la pena.

La multa es la mejor alternativa a la prisión (sobre todo en sociedades capitalistas y consumistas), en la medida en que exista un buen sistema que permita calcularla de forma eficiente en función de la condición económica del condenado. Al respecto, debe tenerse en cuenta la gravedad del delito y la capacidad económica del sujeto activo. Si no se implementa un sistema que permita conocer con certeza estas variables, no se cumpliría realmente con la función preventiva de la pena. Una multa bien calculada puede ser una alternativa a la prisión y, en países como el Perú, incluso puede servir como criterio adicional para determinar las pensiones alimenticias solicitadas en los juzgados de familia.

Ahora bien, para concebir a la multa como un real sustituto de la pena privativa de libertad, es imprescindible dejar de considerarla como un acompañamiento a la pena de prisión para convertirla en una alternativa. Esto, en el Perú, solo será viable en la medida en que el legislador deje de considerar a la pena de prisión como una pena conjuntiva a cualquier otro tipo de sanción, lo que en la práctica no acontece $^{75}$. Para lograr este objetivo será necesario contar con un buen sistema de cuantificación de ingresos, considerando que, por más malo que sea el sistema de cuantificación, nunca será más costoso que la infraestructura de un centro penitenciario. De igual forma, deberá tomarse en cuenta para su imposición la proporcionalidad, en tanto una multa desproporcional devendría en un despropósito a la luz del marco constitucional.

En relación con la sustitución por trabajo en beneficio de la comunidad, cabe mencionar que es adecuado de cara a la función preventiva de la pena, en tanto permite que las personas aprendan de su delito. El problema es que se tarda mucho en cumplirse, por lo que una persona podría no llegar a ver nunca sus antecedentes penales cancelados. Además, debe contar con la aceptación del condenado, en caso contrario,

75 Un ejemplo de ello es el artículo 122 del Código Penal, que sanciona a quien causa a otro un daño en el cuerpo o en la salud que requiera más de diez y menos de treinta días de asistencia o descanso, según prescripción facultativa, con pena privativa de libertad no mayor de dos años y con 60 a 150 días-multa. 
se estarían vulnerando sus derechos. Ello obliga a los jueces a que esta pena siempre sea impuesta de forma alternativa con otra pena, como la multa. En el Perú, existen diversos delitos que contravienen lo señalado, en tanto contemplan como única sanción la prestación de servicios comunitarios. Un claro ejemplo es el artículo 163 del Código Penal peruano, que sanciona únicamente con 20 a 52 jornadas la supresión o extravío indebido de correspondencia. En este caso, la aceptación o no del condenado resulta irrelevante, pues no es posible imponerle una sanción alternativa. Por ello, a la luz del marco constitucional, los tipos penales que solo contemplan como sanción el trabajo en beneficio de la comunidad deben ser modificados incorporándoles una pena adicional, como por ejemplo la multa.

Conforme lo señala el artículo 53 del Código Penal peruano, previo apercibimiento judicial, la conversión quedará revocada en los casos en los que el condenado no cumpla injustificadamente con el pago de la multa o la prestación del servicio asignado a la jornada de limitación de días libres, debiendo ejecutarse la pena privativa de libertad fijada en la sentencia. En esos casos, la pena cumplida será descontada de la privativa de libertad a razón de un día de multa por cada día de privación de libertad, o una jornada de servicio a la comunidad, o una de limitación de días libres por cada siete días de pena privativa de libertad. En igual sentido, en caso que el condenado cometa, dentro del plazo de ejecución de la pena convertida, un delito doloso sancionado con pena de prisión no menor de tres años, también se le revocará la conversión automáticamente, estableciéndose ello en una nueva sentencia condenatoria (previo descuento del tiempo de la parte convertida ejecutada: artículo 54 del mismo cuerpo legal).

La crítica que puede formularse a lo establecido en los artículos 53 y 54 del Código Penal peruano es que, al condicionar la sustitución a la comisión de un nuevo delito doloso, se verifica que el legislador no ha querido realmente regularla como tal. Ello en tanto que, si realmente nos encontráramos frente a una sustitución de pena - la que no podría desaparecer por la configuración de un nuevo delito, pues al haber operado esta no podrían eliminarse sus efectos-, frente a lo que nos encontramos realmente es a una mezcla extraña y sui generis entre sustitución de pena y prevención de la condena.

\section{IV.3. Suspensión de la ejecución de la pena}

La suspensión de la pena de prisión constituye una «segunda oportunidad» ${ }^{76}$ que el juez penal puede brindar al condenado en la 
medida en que cumpla con ciertos requisitos que le son impuestos por un plazo determinado. Estos últimos suelen ser funciones de control dirigidas a superar lo que llevó al sujeto a delinquir y no tienen fundamentalmente un fin de resocialización. Esto ha hecho que en el Perú, de forma indebida, la suspensión se convierta realmente en una medida de gracia para no llenar las cárceles, al igual como ocurre en el ordenamiento español ${ }^{77}$.

Esta institución se encuentra regulada en el artículo 57 del Código Penal peruano, el que permite al juez suspender la ejecución de la pena por un plazo de uno a tres años, siempre que se configuren ciertos requisitos, como: (i) que la condena se refiera a pena privativa de libertad no mayor de cuatro años; (ii) que la naturaleza, modalidad del hecho punible y la personalidad del agente hicieran prever que esta medida le impedirá cometer nuevo delito, y (iii) que el agente no tenga la condición de reincidente o habitual. El artículo 58 del mismo cuerpo legal establece que, al otorgar el juez esta condena condicional, «impondrá» la realización de ciertas conductas. Así, entre las reglas de conducta que el juez puede imponer, se encuentran las siguientes: (i) prohibición de frecuentar determinados lugares; (ii) prohibición de ausentarse del lugar donde reside sin autorización del juez; (iii) comparecer personal y obligatoriamente al Juzgado, para informar y justificar sus actividades; (iv) reparar los daños ocasionados por el delito, salvo cuando demuestre que está en imposibilidad de hacerlo (a diferencia del ordenamiento español, la reparación no es una condición sine qua non para que proceda la suspensión sino que es tomada en cuenta como una regla de conducta $\left.^{78}\right)$; (v) que el agente no tenga en su poder objetos susceptibles de facilitar la realización de otro delito, y (vi) los demás deberes que el juez estime convenientes a la rehabilitación social del agente, siempre que no atente contra la dignidad del condenado.

Ahora bien, en los casos en los que durante el período de prueba el condenado fuera condenado por otro delito o no cumpliera con las reglas de conducta impuestas por el juez, este se encuentra facultado para, según sea el caso, amonestar al infractor, prorrogar el período de suspensión hasta la mitad del plazo inicialmente fijado (sin exceder nunca el plazo los tres años), o revocar la suspensión de la pena (artículo 59 del Código Penal). Esto último, en caso que el agente sea condenado por un nuevo delito doloso cuya pena privativa de libertad sea superior a tres años, supuesto en el cual se ejecutará la pena suspendida condicionalmente y la que corresponda por el segundo delito.

77 lbíd., p. 22.

78 El artículo 81 del Código Penal español establece como requisito para que la suspensión sea posible el haber pagado las responsabilidades civiles que se hubieren originado con el delito, salvo que se demuestre la imposibilidad total o parcial de haberlo. En el ordenamiento peruano, en los casos en los que el juez no considere este requisito como regla de conducta, la no cancelación de la reparación civil no importará para la suspensión de la ejecución de la pena. 
En los casos en los que el condenado cumpliera con las reglas de conducta, no las infringiera persistentemente o no cometiera un nuevo delito doloso, la condena se considera como no pronunciada, sin llegarse a generar antecedentes penales. Este es un aspecto positivo que el legislador ha previsto a la luz del fin preventivo constitucional de la pena, y que debe ser aplicado propiciando dicha resocialización por los jueces penales peruanos.

En la línea de lo expuesto, la suspensión de la pena de prisión no puede ser considerada como una mera medida de gracia: debe ser impuesta por el juez en función de las posibilidades de resocialización del penado, así como a sus condiciones personales. Bajo esta misma lógica, lo establecido en el artículo 58 del Código Penal respecto de la posibilidad que tiene el juez para imponer la realización de ciertas reglas de conducta debe ser interpretado como una facultad para aquel de cara a los fines preventivos de la pena ostenta, y no como una obligación.

Asimismo, la suspensión no debe ser la primera opción con la que cuenten los jueces para el incumplimiento efectivo de la pena privativa de libertad, pues previamente debe recurrirse a otros mecanismos menos gravosos previstos por el ordenamiento jurídico, como es el caso de la sustitución de pena. De esta forma, en caso de poder aplicar el juez penal la sustitución y la suspensión de la condena, deberá preferir la primera. Esto de cara a conseguir los fines de prevención general y especial, perspectiva desde la que es preferible sustituir que suspender la condena de prisión. En esta línea, resulta absurdo que el legislador peruano regule la multa, la limitación de días libres y la prestación de servicios comunitarios, como sanciones conjuntivas a la pena privativa de libertad, debiendo considerarse sanciones alternativas de cara a una sustitución de penas ${ }^{79}$.

\section{IV.4. Prisión preventiva}

La prisión preventiva cobra importancia al amparo del carácter de última ratio del derecho penal. A diferencia de los apartados anteriormente descritos en este punto, no constituye sanción alguna, en tanto es una medida que se impone antes de la expedición de una sentencia condenatoria y en caso concurran ciertos presupuestos procesales que la legitimen. Dado que supone que un individuo vaya a prisión antes de la sentencia condenatoria, debe ser impuesta de forma sumamente excepcional, máxime cuando trastoca la función preventiva de la pena.

79 No me detendré a analizar la expulsión (regulada en los artículos 30 y 303 del Código Penal peruano) debido a que se aplica luego de cumplida la pena que se haya impuesto al extranjero. Esto, a diferencia de lo dispuesto en el artículo 89 del Código Penal español, en el que se regula la expulsión como una medida alternativa de pena. 
Lo expuesto cobra especial relevancia si se toma en cuenta que un individuo en prisión preventiva ni siquiera puede ser resocializado, pues no se encuentra cumpliendo condena penal alguna, lo que evidencia la desnaturalización que de por sí trae esta figura. Por ello, la no aplicación excepcional de la prisión preventiva conlleva a la vulneración de los presupuestos de un Estado social y democrático de derecho, razón suficiente para aplicar esta medida lo más restringidamente posible.

El artículo 135 del Código Procesal Penal (decreto legislativo 638) vigente en algunos distritos judiciales ${ }^{80}$, establece que el juez penal podrá dictar mandato de detención en caso que sea posible determinar: (i) que existen suficientes elementos probatorios de la comisión de un delito que vincule al imputado como autor o partícipe de aquel; (ii) que la sanción a imponerse sea superior a los cuatro años de pena privativa de libertad, y (iii) que existen suficientes elementos probatorios para concluir que el imputado intenta eludir la acción de la justicia o perturbar la acción probatoria. Ahora bien, con relación al hecho de que la pena sea superior a los cuatro años, cabe mencionar que esto no obliga al juez a imponer la prisión preventiva únicamente en estos casos, aunque puede hacerlo también en los supuestos en los que el tipo penal establezca una sanción menor (así viene siendo aplicado en la jurisprudencia), lo que considero totalmente contrario a la naturaleza excepcional que debe revestir esta medida. No obstante, el juez puede revocar de oficio o a petición de parte en cualquier momento dicha medida, en caso que nuevos actos de investigación demuestren que no concurren razones que la legitimen.

Se regula de forma expresa que el plazode detención o prisión provisional no durará más de nueve meses en el procedimiento ordinario, ni más de dieciocho meses en el procedimiento especial (casos de tráfico de drogas y terrorismo). Sin embargo, el artículo 137 del Código Procesal Penal ofrece la posibilidad de duplicar estos plazos, en los casos en los que exista una naturaleza compleja (varios procesados o víctimas), concurran circunstancias que importen una especial dificultad o una especial prolongación de la investigación (y que el inculpado pudiera sustraerse a la acción de la justicia), y cuando el delito se haya cometido a través de una organización criminal y el imputado pudiera sustraerse a la acción de justicia o perturbar la actividad probatoria. Esta ampliación establecida en la ley resulta cuestionable, y aunque los plazos han sido reducidos con la introducción del nuevo Código Procesal Penal, este establece presupuestos, requisitos y plazos muy similares a los del decreto legislativo 638 (artículos 272 y siguientes),

80 Recuérdese que en el Perú existe un cambio normativo en el ámbito procesal que ha llevado a que en diversos distritos judiciales se encuentren vigentes diferentes normas procesales. 
sin haber logrado con su promulgación un progreso o avance con relación a esta materia.

Igual de cuestionable es lo establecido en los casos en los que se haya condenado al procesado en primera instancia, pues en esos casos la ley autoriza que la detención se prolongue hasta la mitad de la pena impuesta cuando esta hubiera sido recurrida. Para el cómputo de los plazos establecidos en este artículo no se toma en cuenta el tiempo en que la causa sufriere dilaciones maliciosas imputables al inculpado o su defensa.

Resulta lamentable observar que la prisión preventiva, en lugar de usarse de forma excepcional, es de uso generalizado, convirtiéndose el primer obstáculo para una reforma penitenciaria. Así, según las cifras difundidas por el INPE, para enero de 2012 los procesados constituían un $58,15 \%$ del total de población carcelaria (30 940 personas), mientras que los sentenciados conformaban un $41,85 \%$, es decir, menos de la mitad (22 263 personas). Asímismo, hay una sobrepoblación del 87\% (la capacidad de albergue es de 28508 y hay 53203 internos) ${ }^{81}$. Cabe señalar también que en estas condiciones de sobrepoblación resulta muy cuestionable conseguir objetivos como la resocialización, por lo que se hace más necesaria e importante la aplicación de mecanismos alternativos a la pena privativa de libertad.

Otro punto criticable a ser atendido en una reforma es el hecho de que en los centros penitenciarios peruanos no se separe a los condenados de los procesados, máxime cuando estos últimos no se encuentran cumpliendo en estricto una pena (sino a la espera de que se les imponga $-\mathrm{O}$ no- una), por lo que no es posible en principio aplicar en ellos políticas de resocialización, y no beneficiarse de los beneficios penitenciarios correspondientes.

A la luz de lo expuesto, resulta imperativo crear mecanismos que permitan al juez penal un adecuado seguimiento de la ejecución de la pena que ha sido impuesta, sea ya en lo referente a la ejecución de la pena privativa de libertad o al cumplimiento de las otras penas que la sustituyen, con la finalidad de que se cumpla la función preventiva de la pena. En esta línea, se sugiere la regulación de un juez de vigilancia penitenciaria que tenga como dedicación exclusiva la revisión de estos supuestos, y no como labor principal (lo que ocurre a la fecha) la resolución de los casos penales. 


\section{EJECUCIÓN PENITENCIARIA: LAS NORMAS \\ PENITENCIARIAS DEBEN SER ACORDES CON LOS FINES PREVENTIVOS DE LA PENA}

Dentro de los principios del derecho penitenciario están el de legalidad ${ }^{82}$, el de resocialización (las leyes deben regularse en función de ella; por ejemplo, el cumplimiento de la pena de prisión debe buscarse lo más cercano al hogar del condenado); de judicialización (debe haber un juez ejecutor de penas) y el de presunción de inocencia. Así, las instituciones penitenciarias siempre deben tener como fin la reeducación y la reinserción social. En esta línea, no se debe confundir régimen penitenciario con tratamiento penitenciario: los principios que inspiran el régimen son el de legalidad, el de subordinación del régimen penitenciario al tratamiento (el régimen está bien siempre y cuando no limite o condicione el tratamiento) y el de coordinación entre tratamiento y régimen ${ }^{83}$.

Actualmente se propone un programa mínimo de resocialización, en el cual la participación del Estado se limita a verificar que, cuando los internos salgan de prisión, no realicen actos violentos. A diferencia de lo que ocurre en el Perú, donde no existen grados de clasificación, en España existen tres grados: el primero corresponde al régimen cerrado; el segundo corresponde al régimen ordinario, y el tercero corresponde al régimen abierto ${ }^{84}$. Asimismo, se hace una evaluación inicial de cada interno al momento en que ingresa para clasificarlo en el grado correspondiente (esto, sin perjuicio de que el grado se revise cada seis meses). Dependiendo del grado en que el interno se encuentre, contará con más o menos beneficios. En el Perú, lamentablemente, los internos ni siquiera se encuentran clasificados por condenados y procesados, lo que da una idea de lo rústico del sistema penitenciario y de lo alejado que se encuentra de los fines preventivos constitucionales de la pena. La lucha gira, antes que nada, en la posibilidad de otorgar condiciones humanas a los internos, lo que impone a gritos la necesidad de una reforma y de un programa integral político criminal que parta desde la determinación de la pena en abstracto.

Con relación a la ejecución de la pena, en el Perú no existe un juez de vigilancia penitenciaria (como sí existe en España ${ }^{85}$ ) lo que de por sí genera una distorsión en el sistema penitenciario y en la ejecución de la pena de cara a la resocialización. Con el nuevo Código Procesal

82 Aunque en el Perú no se exige ley orgánica para restringir derechos, lo cual constituye un gran problema de cara a la seguridad jurídica.

83 Pérez CepedA, Ana Isabel y Julio Fernández García. «Lección 5: El régimen penitenciario». En Ignacio Berdugo Gómez de la Torre (coord.). Ob. cit., pp. 124-125.

84 ZÚÑIGA RODRíGUEZ, Laura. «Lección 6: El tratamiento penitenciario». En Ignacio Berdugo Gómez de la Torre (coord.). Ob. cit., pp. 162 y ss.

85 Sobre este punto, ver PÉREZ CEPEDA, Ana Isabel. «Lección 10: El juez de vigilancia penitenciaria y sus consecuencias». En Ignacio Berdugo Gómez de la Torre (coord.). Ob. cit., pp. 269 y ss. 
Penal, quien se encarga de realizar las labores de ejecución es el juez de la investigación preparatoria, es decir, el juez que se pronuncia respecto del requerimiento fiscal (artículo 48986). Este está facultado para resolver todos los incidentes que se susciten durante la ejecución de las sanciones, así como los pedidos formulados por los internos. Ello constituye un contrasentido, pues en la práctica la mayoría de jueces de investigación preparatoria, que deben conocer las causas pendientes de resolución, se encuentran muy alejados de los centros penitenciarios. Como vemos, no existe un real control respecto del cumplimiento de los fines preventivos de la pena (un ejemplo de ello es el penal de Piedras Gordas en Lima y los penales de Talara y Piura).

Sin perjuicio del claro retraso existente en las normas de ejecución en el país, cabe rescatar la promulgación del decreto legislativo (Código de Ejecución Penal) del 2 de agosto de 1991 y su reglamento (decreto supremo 015-2003-JUS), aunque debe agregarse que estas normas, que no son de aplicación práctica en la realidad, regulan una serie de derechos y beneficios que difícilmente son aplicados por los jueces penales. Así, entre los puntos más saltantes tenemos: la regulación de un régimen penitenciario con visitas y comunicaciones, beneficios penitenciarios, entre otros; la regulación de un tratamiento penitenciario en el que se reconocen derechos como el trabajo, la educación, la salud, la asistencia social, la asistencia legal, la asistencia psicológica y la asistencia religiosa, y ciertas disposiciones relacionadas con la infraestructura de los centros penitenciarios y a la asistencia post penitenciaria. Sin embargo, considero que no tiene sentido profundizar sobre estas disposiciones, en la medida en que no tienen correlato fáctico. Prueba de ello es el alto porcentaje de hacinamiento que caracteriza en promedio a los centros penitenciarios peruanos, lo que hace necesario una inversión en lo referente a su infraestructura.

Con relación a la infraestructura con la que deben contar los penales, cabe señalar que este no ha sido un tema en el que el Estado haya invertido tiempo y recursos. Puede decirse que no existe voluntad política respecto de una reforma. Las condiciones de hacinamiento que existen en los penales fuera de Lima son totalmente contrarias a cualquier fin preventivo constitucional de la pena, pues ni siquiera hay ambientes adecuados para que el interno pueda comunicarse con su abogado en aras de una estrategia de defensa. Esto motivó que incluso el Estado se plantee la posibilidad de — siguiendo el sistema norteamericano_ - privatizar las cárceles, lo que hizo que en determinado momento ProInversión convocara a una subasta pública internacional

FUNCIÓN

CONSTITUCIONAL

ASIgNADA A LA

PENA:

BASES PARA un

PLAN DE POLÍTICA

CRIMINAL

CONSTITUTIONAL

FUNCTION

ASSIGNED TO THE

PENALTY: BASES

FOR A CRIMINAL

POLICY PLAN 
para la concesión de un establecimiento penitenciario en el distrito de Aucallama, provincia de Huaral, en la región Lima.

El concesionario sería responsable del diseño, construcción, equipamiento, mantenimiento y operación por veinticinco años de este penal con capacidad para 1536 internos primarios no reincidentes de Lima, Ica y Áncash y la inversión requerida ascendía a aproximadamente US\$ 30 millones para la construcción y equipamiento del penal ${ }^{87}$. Estas ideas son a mi parecer cuestionables de cara a la función que debe cumplir el Estado respecto de la resocialización, toda vez que conceder a una empresa privada la reinserción social de los internos difícilmente tendría éxito de cara a los objetivos que la Constitución impone al Estado. En tal sentido, es necesario recordar que toda empresa que tenga como objeto lucrar, difícilmente podrá contribuir con la resocialización (los objetivos de una empresa privada no me parecen compatibles con la resocialización del individuo).

La realidad reclama con urgencia un incremento en el presupuesto que el Estado destina a las prisiones, lo que también supone una adecuada capacitación del personal que labora en ellas, así como la creación de servicios necesarios para la resocialización (adecuados sicólogos, psiquiatras, médicos, entre otros).

$\mathrm{Al}$ parecer, tratar y desarrollar esta materia, en tanto acerca a los políticos y legisladores a la realidad carcelaria, produce cierta aversión, lo que pareciera instar al juzgador a tomar distancia de dicha realidad para recurrir al facilismo de fijar penas sin criterios de razonabilidad, motivación, y por justificaciones populistas que no responden a los fines preventivos que la pena cumple en un Estado social y democrático de derecho como es el consagrado en la Constitución peruana.

\section{PROPUESTAS CONCRETAS PARA UNA REFORMA LEGISLATIVA Y BASES PARA UN PROGRAMA INTEGRAL DE POLÍTICA CRIMINAL EN TORNO A LA CONCEPCIÓN CONSTITUCIONAL DE LA PENA}

Las propuestas que se plantean a continuación toman como premisa el hecho de que, si una pena no responde a los fines preventivos establecidos en la Constitución, deviene arbitraria e injusta. En esta línea, el principio de eficacia constituye un principio de política criminal que demanda una permanente evaluación de objetivos, estrategias y resultados ${ }^{88}$. 
Así, para plantear propuestas concretas de un programa integral de política criminal, considero que debe tomarse en cuenta la función preventivo-general y especial que la pena debe cumplir en la determinación de la pena abstracta por el legislador. En esta etapa se proponen las siguientes reformas jurídicas e institucionales:

a) Incrementar la pena mínima de dos días y reducir la pena máxima de 35 años, dado que estos márgenes de sanción penal no viabilizan resocialización alguna: función constitucional asignada a la pena.

b) Eliminar la cadena perpetua, por resultar un sinsentido de cara a los fines preventivos de la pena previstos en el texto constitucional.

c) No sancionar las modalidades culposas con pena privativa de libertad, ya que resulta claro que esta no es la vía idónea para conseguir la resocialización. Para este tipo de delitos son más útiles las otras penas establecidas en la parte general, como la prestación de servicios comunitarios o la multa.

d) Las penas alternativas de prisión o multa, prisión o prestación de servicio comunitario, prisión o limitación de días libres deben ser reemplazadas, eliminando la posibilidad de prisión. El hecho de que el legislador prevea una pena disyuntiva y la posibilidad de elección por el juez supone en el fondo un reconocimiento de que la prisión no es el único mecanismo para alcanzar la función preventiva constitucional de la pena en dichos tipos penales.

e) Deben despenalizarse los tipos penales simbólicos, en tanto el derecho penal debe siempre limitarse por los principios constitucionales de lesividad y mínima intervención.

f) Es necesaria una revisión de las penas impuestas en el Código Penal, en tanto muchas no siguen los criterios de proporcionalidad y subsidiariedad.

g) Es necesario difundir entre la población que el incremento de penas no redunda necesariamente en la reducción de la inseguridad ciudadana.

Con relación a la individualización judicial que los jueces hacen de la pena en cada caso concreto (pena concreta), un programa integral de política criminal debe tomar en cuenta la función preventivo-especial que la pena cumple en la determinación de la pena concreta por el juez. Así, se proponen las siguientes reformas jurídicas e institucionales:

a) La reserva del fallo condenatorio y la exención de pena, en tanto no suponen la imposición de aquella, deben ser preferidas respecto de la sustitución. Con mayor razón, estas deben preferirse en el caso de los delitos imprudentes. 
b) La creación de un buen sistema de cuantificación de ingresos a efectos de la determinación de los días multa. Este debe tomar en cuenta la gravedad del delito y la capacidad económica del sujeto activo. La pena de multa debe dejar de ser un acompañamiento a la pena privativa de libertad (debe dejar de ser regulada por el legislador como una pena conjuntiva). El juez debe tomar en cuenta la proporcionalidad al momento de determinar la pena de multa.

c) La sustitución de la pena privativa de libertad con el trabajo en beneficio de la comunidad debe contar con la aceptación del condenado, por lo que los jueces siempre deben imponerla de forma alternativa con otra pena (como la de multa); dado que el penado puede negarse a cumplirla. En tal sentido, deben modificarse los delitos que solo contemplan a esta como pena, y evaluarse si dichas conductas realmente deben ser protegidas por el derecho penal.

d) El trabajo en beneficio de la comunidad debe ser la pena considerada por los jueces como la más acertada para los tipos imprudentes, ello de cara a la prevención y la resocialización de la pena.

e) La sustitución de la pena privativa de libertad no puede estar condicionada a la comisión de un nuevo delito doloso.

f) La suspensión de la pena de prisión no puede ser considerada como una mera medida de gracia. Las reglas de conducta que el artículo 58 del Código Penal prevé no son de obligatoria imposición el juez, sino una facultad para él en función de las posibilidades de resocialización del condenado y el objetivo preventivo de la pena.

g) En caso de que el juez penal pueda aplicar la sustitución y suspensión de la condena, deberá preferir la primera.

h) Las penas de multa, limitación de días libres y prestación de servicios comunitarios no pueden ser reguladas como sanciones conjuntivas a la pena privativa de libertad: deben considerarse sanciones alternativas de cara a una sustitución de penas.

i) La prisión preventiva debe usarse de forma excepcional y no de modo generalizado. Debe evitarse para los casos en los que la pena prevista en el tipo penal sea menor a los cuatro años. Es necesaria una reforma legislativa que reduzca los plazos de prisión preventiva en lugar de ampliarlos, como ocurre a la fecha.

j) Es urgente la creación de un juez de vigilancia penitenciaria distinto del que conoce el proceso, de cara a un adecuado cumplimiento de la pena impuesta, la que no siempre implica 
la pena privativa de libertad (léase: prestación de servicio comunitario, días multa, entre otros).

k) La Academia de la Magistratura debe impartir cursos en relación con la función preventiva que la pena cumple en un Estado social y democrático de derecho como el peruano, y con relación a los mecanismos de individualización judicial de la pena, pues existe un gran desconocimiento en la materia.

1) Debe fomentarse en las instituciones privadas el dictado de conferencias y cursos que reúnan a los operadores judiciales, con el fin de viabilizar una uniformidad de criterios en la jurisprudencia.

Por último, con relación a la ejecución penitenciaria de la pena, me permito proponer las siguientes pautas hacia una reforma que respete y valore los fines preventivos constitucionales de la pena:

a) Inversión del Estado en la infraestructura de los centros penitenciarios en todo el Perú, con el fin de dotarlos de espacios y celdas que permitan a los internos vivir en condiciones dignas que garanticen sus derechos; en caso contrario, será imposible plantear cualquier tipo de resocialización.

b) Capacitación y contratación de personal adecuado para los centros penitenciarios, con el fin de permitir una resocialización.

c) Revisión de los niveles de seguridad y control para el acceso de las visitas a los penales, para evitar el ingreso de bienes que dificulten la resocialización.

d) Separación de los internos que se encuentran cumpliendo en estricto una pena de quienes se encuentran a la espera de que se les imponga $\longrightarrow$ no- - a una.

e) Replanteamiento general del sistema penitenciario y establecimiento de una clasificación de los internos por grados, lo que necesariamente supone una gran inversión en infraestructura del Estado.

FUNCIÓN

CONSTITUCIONAL

ASIGNADA A LA

PENA:

BASES PARA UN

PLAN DE POLÍTICA

CRIMINAL

CONSTITUTIONAL

FUNCTION

ASSIGNED TO THE

PENALTY: BASES

FOR A CRIMINAL

POLICY PLAN 